\title{
NUEVOS DATOS SOBRE CALIGRAMAS
}

\author{
Por \\ Miguel D'ORS
}

\begin{abstract}
A poco de completarse el tercer cuarto del siglo pasado publiqué un librito que pretendía trazar una historia universal del caligrama ${ }^{1}$ desde sus orígenes hasta su popularización vanguardista en los primeros años de aquella centuria y ofrecer una selección de ejemplos significativos. ${ }^{2}$ Era el primer intento español de abordar global y pormenorizadamente el tema, y la novedad y la osadía del empeño explicaban y compensaban, creo, las imperfecciones con que se llevó a la práctica. ${ }^{3}$
\end{abstract}

${ }^{1}$ En aquellos momentos la palabra caligrama no había sido admitida todavía en el diccionario de la Real Academia Española, y por eso opté por escribirla en letra cursiva. Aparece por primera vez en la $21^{\mathrm{a}}$ edición del DRAE (1992), con la siguiente definición: «Escrito, por lo general poético, en que la disposición tipográfica procura representar el contenido del poema». Una vez naturalizado oficialmente el término en la lengua española, no hay razón para seguir poniéndolo en cursiva.

${ }^{2}$ El caligrama, de Simmias a Apollinaire. Historia y antología de una tradición clásica, Ediciones Universidad de Navarra, S. A., Pamplona, 1977.

${ }^{3}$ Escribo esto bien consciente de que no todo el mundo comparte esta piadosa opinión. Antonio Chicharro Chamorro, "Notas para un análisis de "la poesía concretovisual", Estudios sobre Literatura y Arte dedicados al profesor Emilio Orozco Díaz recogidos y publicados por A. Gallego Morell, Andrés Soria y Nicolás Marín, Universidad de Granada, 1979, I, p. 379, n. 1, reprocha a mi estudio como también al de Armando Zárate Antes de la vanguardia. Historia y morfología de la experimentación visual de Teócrito a la poesía concreta, Rodolfo Alonso Editor, Buenos Aires, 1976- el que considere «la experimentación visual a lo largo de la historia como una constante» y no se plantee el caligrama "actual" (del que, soit dit en passant, mi investigación no se ocupaba, según indica ya su título y confirma el encabezamiento de su último apartado: "Epílogo: Apollinaire y el caligrama moderno") "como algo que no tiene nada que ver, por ejemplo, 


\section{Subsanar en cierta medida esas imperfecciones, ofreciendo algunos datos que en 1977 no conocía y a partir de entonces he ido descubriendo, bien a través de publicaciones ajenas, ${ }^{4}$ bien por mis}

con la Grecia clásica. Pensar de esta manera no conduce en ningún momento a un conocimiento válido de lo que pueda ser la poesía experimental». A juicio del crítico, aunque ese historicismo evolucionista puede proporcionar algunos datos verdaderos, mi libro, contemplado en su totalidad, sólo ofrece conocimiento ideológico. Claro que tampoco en este punto es todo el mundo de la misma opinión: Giovanni Pozzi, en La parola dipinta, Adelphi Edizioni, Milano, 1981 (2ª ed., corregida y aumentada, 2002, que es la que he manejado, p. 351), sostiene: «Importa comunque il riconoscimento [...] che gli esperimenti contemporanei sulla scrittura e gli alfabeti si congiungano alla linea secolare della poesia visiva. È un punto ormai acquisto, ripetuto immancabilmente da esperti d'ambo i campi». Si el sentido último de esos asertos de Chicharro es que, más allá de sus semejanzas formales, hay entre el caligrama griego -o el "antiguo" en general-y el "actual" sustanciales diferencias de intencionalidad, debo decir que me parecen de un excesivo simplismo: puestos a hacer distingos, no hay más remedio que reconocer que tampoco todos los caligramas actuales obedecen a las mismas intenciones. Los de González Estrada, por ejemplo, es evidente que corresponden a propósitos muy distintos que el de Lewis Carroll o los de Apollinaire, por más que unos y otros fuesen compuestos en fechas próximas. Paralelamente, en el ámbito de los siglos XVI y XVII los propósitos del autor del enésimo caligrama nupcial alemán en forma de copa tampoco tienen mucho que ver con los de un Scaligero o con los de los alumnos de Retórica y Poética de cualquier colegio de la Compañía de Jesús. Pero, puesto que el caligrama se define primordialísimamente en el plano formal, no parece descabellado contemplarlo e inventariarlo desde el punto de vista formal. Por su parte, Víctor Infantes de Miguel, "La textura del poema: disposición gráfica y voluntad creadora", 1616. Sociedad Española de Literatura General y Comparada, III, 1980, p. 82-89, se escandalizó de que yo declarase no conocer ningún caligrama español de los Siglos de Oro (si bien me había cuidado de puntualizar cautelosamente: «pero no excluyo la posibilidad de que haya existido alguno, aunque es indiscutible que se tratará de casos aislados, pues España no tuvo un humanismo renacentista suficientemente fuerte en lo relativo al griego para asimilar y prolongar la tradición del technopaegnion», y en una larga nota hacía referencia a la existencia, ésta sí bien documentada, de otros artificios próximos al caligrama); se escandalizó, digo, porque, ay de mí, existía, según él, uno ("caso aislado" por lo tanto: no andaba yo tan descaminado), y lamentó por ello "la falta de documentación y apresuradas conclusiones del trabajo de D'Ors $[$ sic]" (p. 88). Siempre he sido el primero en dolerme de mi ignorancia, pero en este punto, a la luz de las palabras de mi libro que acabo de recordar, no me parece tan grave. En todo caso, por las razones que habrá ocasión de ver en el texto más adelante, no mucho más grave que la de mi áspero detractor.

${ }^{4}$ Los estudios sobre las relaciones entre poesía e imagen, sobre poesía visual y sobre el caligrama en particular han conocido un llamativo desarrollo desde aquellas fechas. En relación con nuestro tema, cf. los dos trabajos mencionados en la nota anterior y además Dick Higgins, George Herbert's Pattern Poems: In Their Tradition, Unpublished Editions, West Glover, Vermont and New York, 1977; Philippe Dubois, "Palindromi i carmina figurata", Knjizeva kritika, 4, 1977, p. 19-30; Jérôme Peignot, Du calligramme, Éditions du Chêne, Paris, 1978; Laura Simo- 
nini-Flaminio Gualdoni, Carmi figurati greci e latini, La Nuova Foglia, Polenza, 1978; Armando Zárate, "Los textos visuales de la época alejandrina", Dispositio, III, 9, 1978, p. 353-366; Peter Mayer, "A Chronology of Visual Poetry", en Bob Cobbing-Peter Mayer, Concerning Concrete Poetry, Writers Forum, London, 1978, p. 63-70; Juan Manuel Bonet, "El caligrama y sus alrededores", Poesía, 3, 1978, p. 8-26; Javier Ruiz, "Laberintos y Pentacrósticos de El Pistón”, Poesía, 3, 1978, p. 115-122; Ana Hatherly, Para uma arqueologia da poesia experimental, Colóquio Artes, Lisboa, 1979; Dick Higgins, "The strategy of visual poetry", Precisely, 3-5, 1979, p. 41-59; David William Seaman, "Early French Visual Poetry", Precisely, 3-5, 1979, p. 203-237; Elizabeth Cook, "Figured Poetry", Journal of the Warburg and Courtauld Institutes, 42, 1979, p. 1-15; Víctor Infantes de Miguel, "Algunas de las poesías + extravagantes de la lengua castellana", Poesía, 5-6, 1979-1980, p. 233-244; István Kilián, “A régi magyar képvers”, Új írás, 11, nov. 1980, p. 30-34; Piotr Rypson, "La Tradición de la poesía visual", Arquitecto, 18, 1980, p. 53-58; Giovanni Pozzi, La parola... (cit. en la nota anterior); David W. Seaman, Concrete Poetry in France, UMI Research Press, Ann Harbor, 1981; César Chaparro Gómez, "Acercamiento a los carmina figurata: P. Optaciano Porfirio (C. XXVI)", Anuario de Estudios Filológicos, IV, 1981, p. 55-69; Víctor Infantes, "La poesía experimental antes de la poesía experimental", Encuentros con la poesía experimental, Euskal Bidea, s. 1., 1981, p. 99-131; Ulrich Ernst, "Europäische Figurengedichte in Pyramidenform aus dem 16. und 17. Jahrhundert", Euphorion, 76, 1982, p. 295-360; Jeremy Adler, "Technopaigneia, carmina figurata and Bilder-Reime: Seventeenth-century figured poetry in historical perspective", Comparative Criticism, 4, 1982, p. 107-147; Ana Hatherly, A experiencia do prodígio. Bases teóricas e antologia de textos-visuais portugueses dos séculos XVII e XVIII, Imprensa Nacional-Casa da Moeda, Lisboa, 1983; Giovanni Pozzi, Poesia per gioco. Prontuario di figure artifiziose, Il Mulino, Bologna, 1984; Ulrich Ernst, "Zahl und Mass in den Figurengedichte der Antike und des Frühmittelalters, Beobachtungen zur Entwicklung tektonischer Bauformen”, en A. Zimmermann (ed.), Mensura. Mass, Zahl, Zahlensymbolik im Mittealalter, W. de Gruyter, Berlin, 1984, p. 310-332; Ulrich Ernst, "Poesie und Geometrie, Betracht ungen zu einem visuellen Pyramidengedicht des Eugenius Vulgarius", en K. Grubmüller- R. Schmidt-Wiegand- K. Speckenbach (eds.), Geistliche Denkformen in der Literatur des Mittealalters, W. Fink, München, 1984, p. 321325; Ulrich Ernst, "Lesen als Rezeptionsakt, Textpräsentation und Textverständnis in der manieristischen Barocklyrik", Zeitschrift für Literaturwissenschaftund Linguistik, 57-58, 1985, p. 67-94; Giovanni Pozzi, "Le parole nel disegno e i disegni nelle parole", en A. Asor Rosa (dir.), Letteratura italiana, VI, Einaudi, Torino, 1986, p. 440-442; "Pattern Poetry: a Symposium", Visible Language, 20, 1986; Ulrich Ernst, "Die neuzeitliche Rezeption des mittelalterlichen Figurengedichtes in Kreuzform", en P. Wapnewski (ed.), Mittelalter-Rezeption, J. B. Metzler, Stuttgart, 1986, p. 177-233; Ulrich Ernst, "The Figured Poem: Towards a Definition of Genre", Visible Language, 20-1, 1986, p. 8-27; Dick Higgins, Pattern Poetry. Guide to an Unknown Literature, State University of New York Press, Albany, 1987; Jeremy Adler-Ulrich Ernst, Text als Figur. Visuelle Poesie von der Antike bis zur Moderne, VCH, Weinheim, 1987; Giovanni Polara, "Optaziano Porfirio tra il calligramma antico e il carme figurato di età medioevale", Invigilata Lucernis, 9, 1987, p. 163-173; Ulrich Ernst, "Gattungstheoretische Reflexionen zum Figurengedicht", Wuppertaler Broschüren zur Allgemeinen Literaturwissenschaft, 
propias averiguaciones, es el objeto de estas páginas - que no dudo podrán, a su vez, ser ampliadas y rectificadas en el futuro. ${ }^{5}$

\section{Bibliografía}

Para empezar, en la bibliografía que consigné en las p. 13-15, y más en particular en la parte relativa a Grecia, omití (por "falta de documentación", ciertamente), y puedo agregar ahora, el artículo de N. Wilbur Helm, "The Carmen Figuratum as shown in the works of Publilius Optatianus Porphyrius". ${ }^{6}$ Tampoco cité, en relación con los $\tau \varepsilon \chi v o \pi \alpha i ́ \gamma v ı \alpha$ medievales, el libro de Luciano Caruso y Giovanni Polara, Iuvenilia Loeti. Raccolta di poeti latini-medievali, ${ }^{7}$ ni el artículo del propio Caruso "La poesia

1, 1987, p. 35-69; Giovanni Polara, "Le riprese della poesia figurata nella tarda antichità e nell'alto medievo latino", Annali della Facoltà di Lettere e Filosofia dell'Università di Napoli, 30 (18 de la nueva serie), 1987-1988, p. 339-361; Kilián István, "Figurengedichte im Spätbarock", en B. Köpeczi-A. Tarnai (eds.), Laurus austriaco-hungarica, Literarische Gattungen und Politik in der zweiten Hälfte des 17. Jahrhunderts, Verlag des österreichischen Akademie der WissenschaftenAkadémiai Kiadó, Wien-Budapest, 1988, p. 119-179; Pietor Rypson, Olraz slowa historia paezjiwizualnej, Warszawa, 1989; Ulrich Ernst, "Kommentare zu Flugblättern mit Figurengedichten", en W. Harms-M. Schilling (eds.), Die Sammlung der Herzog-August-Bibliothek in Wolfenbüttel, III, 3, Max Niemeyer Verlag, Tübingen, 1989, p. 48-59; Ulrich Ernst, "Labyrinthe aus Lettern, Visuelle Poesie als Konstante europäischer Literatur", en W. Harms (ed.), Text und Bild, Bild und Text (DFG-Symposion 1988), J. B. Metzler, Stuttgart, 1990, p. 197-215; Ulrich Ernst, "Optische Dichtung aus der Sicht der Gattungs- und Medientheorie", en U. ErnstB. Sowinski (eds.), Architectura poetica, Festschrift fur J. Rathofer, Böhlau, Köln, 1990, p. 401-418; Nicole Marie Mosher, Le texte visualisé. Le calligramme de l'époque alexandrine à l'époque cubiste, Lang, Frankfurt a M., 1990; Rafael de Cózar, Poesía e imagen. Formas difíciles de ingenio literario, Ediciones El Carro de la Nieve, Sevilla, 1991; Giovanni Polara, "Le parole nella pagina: grafica e contenuti nei carmi figurati latini", Vetera Christianorum, 28, 1991, p. 291336; Ulrich Ernst, Carmen figuratum. Geschichte des Figurengedichts von den antiken Ursprüngen bis zum Ausgang des Mittelalters, Böhlau, Köln-WeimarWien, 1991; Poesure et Peintrie. Centre de la Vieille Charité 12 fevrier 1993-23 mai 1993, Musée de Marseille, 1993; Testo e immagine nell'alto medioevo. 15-21 aprile 1993, Centro italiani di studi sull'alto medioevo, Spoleto, 1994.

${ }^{5}$ Al final de mi libro incluí (p. 121-123) una "Nota" con una relación de obras en las que me constaba o sospechaba que había caligramas o referencias al caligrama. Dado que los descubrimientos que he venido haciendo a partir de 1977 apenas han reducido aquella lista, es presumible que hay aún bastante que ampliar y rectificar en la historia universal del caligrama.

${ }^{6}$ Transactions and Proceedings of the American Philological Association, XXXIII, 1902, p. xliii-xlix.

${ }^{7}$ Lerici Editore, Roma, 1969. Hay una segunda edición, aumentada, en Belforte, Livorno, 1993. 
figurata nell'Alto Medioevo", ${ }^{8}$ ni el de Paul Zumthor "Carmina Figurata" ${ }^{9}$ Entre los estudios sobre el caligrama en Grecia, Roma y la Edad Media debió haber sido mencionado el de W. Deonna, "Les "poèmes figurés". ${ }^{10}$ De los technopaegnia barrocos alemanes se ocuparon Robert G. Warnock y Roland Folter en "The German Pattern Poem: A Study in Mannerism of the Seventeenth Century", ${ }^{11}$ investigación que yo desconocía (y sigo desconociendo). Omití también algunos estudios de alcance general, como el de David William Seaman sobre "The development of visual poetry in France", ${ }^{12}$ el curiosísimo libro de Eduardo de Ory Rarezas Literarias, ${ }^{13}$ el artículo de Peter Mayer "Framed and Shaped Writing", ${ }^{14}$ el de Arturo del Villar "De la palabra mágica al caligrama" 15 y el de Ulrich Ernst "Die Entwicklung der optischen Poesie in Antike, Mittelalter und Neuzeit". ${ }^{16}$ Sigo sin conocer el libro de Berjouhi Barsamian Bowler The Word as Image. ${ }^{17}$ Del caligrama en Grecia, Roma, la Edad Media y el Renacimiento trata, como de otras formas antiguas y contemporáneas de poesía visual, el interesante trabajo de Armando Zárate Antes de la vanguardia..., ya citado en la nota 3 , que no tuve tiempo de conocer antes de entregar el mío a la imprenta.

\section{Grecia}

A propósito del caligrama griego, añadiré a todo lo que dije en la p. 19 de mi trabajo que W. Deonna rechaza la idea, expuesta por U. von Wilamowitz y por $\mathrm{H}$. Rosenfeld, de que el caligrama tiene su origen en las inscripciones que se hacían sobre objetos presentados en ofrendas y exvotos. Sostiene, en cambio, que la creación

\footnotetext{
${ }^{8}$ Atti dell'Accademia di Scienze Morali della Società Nazionale di Scienze, Lettere ed Arti in Napoli, 82, 1971, p. 313-375.

${ }^{9}$ Change, 4, 1969, p. 148-159.

${ }^{10}$ Revue de Philologie, L, 1926, p. 187-193.

${ }^{11}$ Festschrift für Detlev W. Schumann, Delp, München, 1970, p. 87-96.

${ }^{12}$ Visible Language, 6-1, Winter 1972, p. 19-44.

${ }^{13}$ M. Cerón Bohórquez, Cádiz, s. a. [pero de fecha posterior a la de Las poesías más extravagantes de la lengua castellana de Agustín Aguilar y Tejera, ya que Ory cita esta obra en el prólogo].

${ }^{14}$ Studio International, 127, 1968, p. 110-114.

${ }^{15}$ La Estafeta Literaria, 573, 1 oct. 1975, p. 4-7.

${ }^{16}$ Germanisch-Romanische Monatsschrift, 26, 1976, p. 379-386.

${ }^{17}$ Studio Vista, London, 1970.
} 
de textos de ese género es algo instintivo y universal. ${ }^{18} \mathrm{El}$ propio Deonna toma de M. Berger la noticia de la existencia de un asa de ánfora púnica, encontrada en Cartago, en la cual las letras del nombre de Baal se disponen formando la imagen cónica del dios Tanit. ${ }^{19}$

Dick Higgins recoge ${ }^{20}$ de la Griekische Paleographie de Viktor Gardthausen $^{21}$ (p. 61) un technopaegnion paleocristiano en griego, en forma de cruz, del que dice es "the earliest known cross-shaped poem". Al emperador Manuel I Commeno (1143-1180) se debe otro texto-cruz en griego, editado en la Paleographia Graeca de Bernard de Montfauçon. ${ }^{22}$

\section{La Edad Media}

Higgins menciona en su libro ${ }^{23}$ otro caligrama-cruz, que puede verse en el Ricoldi ordinis praedicatorum contra sectam Mahometicam [...] libellus de Riccoldo da Monte Croce (1242-1320). ${ }^{24}$ Otro en forma de cátedra - con el respaldo cubierto con un paraguas- es, según nos ha hecho saber Giovanni Pozzi, ${ }^{25}$ la composición que lleva el número 248 en el Canzoniere de Nicolò de'Rossi (ca. 1290-ca. 1348), que es a la vez un acróstico-mesóstico. Se trata de un soneto en italiano, al que acompañan unas instrucciones en prosa latina sobre el orden que ha de seguirse para una correcta lectura. ${ }^{26} \mathrm{Y}$ otro soneto del mismo autor, precisamente el que lleva el número 247, se organiza, con arreglo a los mismos criterios, en forma de estrella. ${ }^{27}$

Al siglo XIII corresponden seis caligramas en prosa latina con forma de jarrón o urna y uno que diseña una arcada, todos con elementos dibujados, que corresponden a meditaciones sobre el Evangelio de San Juan, 2, 6, y se encuentran en el $m s$. anónimo

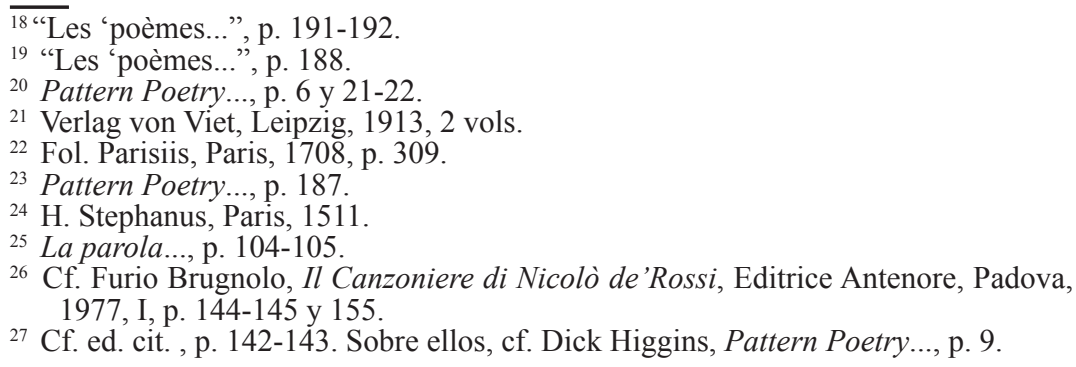


"clm 7960" de la Bayerische Staatsbibliothek de Munich. Los menciona Higgins, quien reproduce dos de ellos (p. 9 y 188).

Debo, por otra parte, a una carta personal de Dick Higgins, el conocimiento del Liber de Distinccione Metrorum (¿1353?) de Iacobus Nicholai de Dacia (o Jakob Nielsen, $f$.1363-1379) ${ }^{28}$, donde, aparte otros poemas en los que los artificios, visuales o no, desempeñan una función relevante, hay algunos que se disponen en forma de triángulo (número $\mathrm{XXV}$ ), cuadrados concéntricos (XXVII, XXVIII), estrella (XXIX) y rueda (XXXI), con mesósticos y telésticos superpuestos. ${ }^{29}$

\section{El Renacimiento}

En relación con el caligrama renacentista, debería yo haber sabido que Michel de Montaigne (1533-1592), en uno de sus Essais, titulado, en traducción española, "De las vanas sutilezas", escribe lo siguiente:

Existen sutilezas frívolas y vanas, mediante las cuales buscan a veces laspersonas el renombre, como por ejemplo, los poetas que logran obras enteras cuyos versos comienzan todos con una misma letra; vemos también huevos, esferas, alas y hachas, que los griegos componían antiguamente con versos rimados, alargándolos o acortándolos de manera que representaran tal o cual figura; no era otra la ciencia del que se entretuvo en contar de cuántos modos podían colocarse las letras del alfabeto, el cual encontró inverosímil el número que se lee en Plutarco. ${ }^{30}$

Testimonio que ha de situarse entre los de Jean Antoine de Baif y A. Canel que cité en la p. 24 de mi trabajo.

Armando Zárate, en el suyo ya mentado ${ }^{31}$ incluye a "Claude Auberi”, que supongo será Claude Aubery $(+1596)$, entre los autores franceses del Renacimiento que compusieron caligramas. No son tales en sentido estricto los cuatro textos "À Dieu" en forma

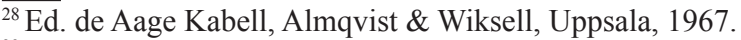

${ }^{29}$ No escaparon a la perspicacia de Giovanni Pozzi, que en diversos pasajes de $L a$ parola... hace referencias a algunos de ellos. Cf. también Dick Higgins, Pattern Poetry..., p. 9.

${ }^{30}$ EDAF, Madrid, 1971, p. 311.

31 Antes de la vanguardia..., p. 57.
} 
de pirámide decreciente publicados por Jean de Boyssières (1555ca. 1583), ${ }^{32}$ que cita y copia Higgins. ${ }^{33}$ Éste menciona asimismo dos series de caligramas en forma de alas, editadas (f. 23v, 29r, y $29 \mathrm{v}$ ) en el Inscriptionum libri duo de Jean Visagier, o Voulté, o Iohannis Vulteus Rhemus $(+1542){ }^{34}$

Por el sabio libro de Giovanni Pozzi ${ }^{35}$ he tenido noticia de que en la novela Hypnerotomachia Poliphili de Francesco Colonna ${ }^{36}$ aparecen varios caligramas -una fuente (p. 107), un cestillo (p. 249), un brasero (p. 278), tres copas (p. 294, 297, 324) y un trípode (p. 342)-, que el estudioso italiano conjetura pudieran ser manifestación de una voluntad de prolongar la tradición alejandrina de Simmias o Teócrito, que Colonna conocería por manuscritos o por la edición impresa de Teócrito que hizo en 1496 Aldo Manucio, más tarde editor de la propia Hypnerotomachia. El mismo Pozzi (p. 197) cita un epigrama de Antonio Telesio (1482-1542), incluído en sus Poemata, ${ }^{37}$ que dibuja las alas de Eros, y otros cinco caligramas, ${ }^{38}$ también en latín, recogidos en los Epigramaton libri decem. Epigramaton libri decem decados secundae de Lancino Curzio $(+1511):{ }^{39}$ unas alas (f. 126v), un pájaro con un acróstico (f. 130v), unas alas dobles también con acróstico (f. 143r) y dos textos con forma (el primero poco claramente) priápica (f. 133r y 137r). Tanto estos últimos como el poema-pájaro suponen aportaciones originales a la tradición del technopaegnion. Asimismo cita Pozzi (p. 199) el caso de Giovan Battista Pigna (1529-1575), autor de tres composiciones que evocan la siringa de Teócrito en el tercero de sus Carminum liber quattuor ${ }^{40}$ (p. 97-99), y el de Guillaume Blanc, que entre sus Epigrammata [...] in obeliscum mirae magnitudis ex Aegypto quondam a Caio Caligula romam advectum et deinde in circo Vaticano erectum iamque ruderibus

\footnotetext{
32 Les troisièmes oeuvres de Boyssières, L. Cloquemin, Lyon, 1579, p. 74-75.

${ }^{33}$ Pattern Poetry..., p. 11 y 66.

${ }^{34} \mathrm{Sim}$. Colimaeum, Paris, 1538.

${ }^{35}$ La parola..., p. 194-195.

${ }^{36}$ Aldo Manuzio, Venezia, 1499. Hay una edición moderna del propio Giovanni Pozzi y Lucia A. Ciapponi, Editrice Antenore, Padova, 1980, 2 vols.

${ }^{37}$ F. Minilii Calvi, Roma, 1524.

${ }^{38}$ La parola..., p. 197.

${ }^{39}$ Apud Rochum et Ambrosium fratres de Valle impressores, Philippus Foyot faciebat, Mediolani, 1521.

${ }^{40}$ Officina Erasmiana Vincentii Valgrisii, Venetiis, 1553.
} 
pene obrutum in mediam s. Petri aream a Sixto $V$ pont. max. translatum et superimposita cruce christianae religioni dicatum ${ }^{41}$ recoge (p. 13) un poema-pirámide.

A despecho de los datos ofrecidos por Margaret Church, que yo asumí en mi libro, sobre el caligrama en la Inglaterra renacentista, Pozzi (p. 200) considera a Richard Willis el "primo poeta figurale inglese". No obstante, para Dick Higgins ${ }^{42}$ el primer caligrama inglés, que tiene forma de pilar, es un poema de amor impreso en la Ekatompathia, or Passionate centrie of Love (1582) de Thomas Watson (¿1557-1592). ${ }^{43}$ De él reproduce (p. 104) las dos versiones gráficas, en la segunda de las cuales se pierde la disposición expresiva. Los carmina figurata presentan en Inglaterra, a juicio de Higgins (p. 95-96), algunas peculiaridades: no suelen apartarse de los modelos formales consagrados, siguiendo las recomendaciones del Arte of English Poetry de Puttenham; se recogen habitualmente en libros, y no en folletos u hojas sueltas como en Alemania, y tienden a agruparse en series. Thomas Blenerhasset (ca. 1550-ca. 1625) incluyó en A revelation of the true Minerva (1582) 4n $^{4}$ unjaro (f. 1v), un rombo (f. 2r) y unas alas (f. 2v). El rey Jacobo VI de Escocia (I de Inglaterra) (1566-1625) compuso un caligrama en forma de monumento, impreso en The essayes of a prentise, in the divine arte of poesie (1585)..$^{45} \mathrm{Un}$ altar en griego, de autor desconocido, se encuentra en Peplus Illustrissimi viri D. Philippi Sidnaei supremis honoribus dictatus, ${ }^{46}$ folleto de homenaje a Philip Sydney atribuido a John Lloyd. Otro libro de homenaje a Sydney, Exequiae illustrissimi equitis D. Philippi Sidnaei, gratissimae memoriae ac nomini imprensae, ${ }^{47}$ contiene una pirámide en prosa latina de Sir William Gager (f. C2v), dos monumentos de Richard Latewar (f. E4r y E4v) y unas alas de Henry Price (f. G4r), todo en latín también. De Andrew Willett

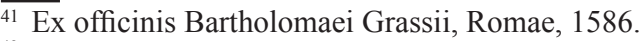

42 Pattern Poetry..., p. 11 y 103-104.

${ }^{43}$ Ed. de Edward Arber, s. e., London, 1870, p. 81-82.

44 Ed. de Josephine Walters Bennett, Scholars Facsimiles and Reprints, Gainesville, FL., 1941.

${ }^{45}$ Cf. The Poems of King James VI, ed. de James Craigie, Blackwood, Edinburgh, 1958.

46 Joseph Barnes, London, 1587.

${ }^{47}$ Ex officina typographica Josephi Barnesi, Oxford, 1587.
} 
(o Wilett) (1562-1621) se editan un árbol en latín (f. A4v) y otros dos poemas, uno en latín y el otro en inglés, que podrían verse como altares o alas, en su Sacrorum emblematum century una. ${ }^{48}$ Sobre Richard Puttenham, a quien mencioné en la p. 29 de mi trabajo, y más concretamente sobre su relación con los caligramas orientales, a los que él hizo referencia en el Arte of English Poetry (1589), puedo citar ahora el artículo de A. L. Korn "Puttenham and the Oriental Pattern-Poem" 49

Para Dick Higgins (p. 71-72) el más antiguo carmen figuratum alemán es un texto esculpido en forma de espiral por Erhard Falkener en la sillería del coro de la iglesia de San Valentín, en Kiedrich, en torno a 1510. En 1561 se editó en Praga el Prima farrago sacri argumenti poematum ab aliquot studiosis [...] scriptorum de Tomás Mitis (1523-1591), ${ }^{50}$ en cuyo f. $82 \mathrm{r}$ aparece un poema-copa. De 1578 es otra copa en latín, "Munus honorarium", hecha por Matthäus Philomates para conmemorar la boda de Albert von Firstenberg e Isabella von Pernstein, que Georgius Nigrinus imprimió en Praga en una hoja suelta. Cita también Higgins un Teutsch Carmen con un acróstico-teléstico caligramático de autor anónimo, que diseña un corazón, compuesto para la felicitación del Año Nuevo 1580 de Johann Feyerabend. Para el matrimonio de Joachim Golz se tiró un folleto de Encomia et vota, ${ }^{51}$ en el que figura (p. 6) otro caligrama-cáliz (o copa), original de Michael Nanticovius. Con motivo del enlace de Johann Adolf von Glauburg se editó -Frankfurt, 1591- otra copa en latín. Jeremy Adler menciona y copia en su artículo citado ${ }^{52}$ otro texto latino en forma de copa, con un acróstico inscrito en letras rojas, y otro con silueta de corazón, compuestos por Bernhard Praetorius (1567-1616) para conmemorar en 1593 el matrimonio del Landgrave Moritz de Hesse y la Condesa Agnes de Solms. ${ }^{53}$ El de Philipp Fugger y Barbara von Kirchberg and Weissenhorn se celebró con un texto

\footnotetext{
$\overline{48}$ Ex officina Iohannis Legate Academiae Cantagriegiensis Typographi, Cambridge, 1596.

49 Comparative Literature, VI, 1954, p. 289-303.

${ }^{50}$ Iohannes Cantor, Praha, 1561.

${ }^{51}$ Georgius Nigrinus, Praha, 1591.

52 "Technopaigneia, carmina figurata...", p. 125-126.

${ }^{53}$ Alcimedontis Poculum Illustriss. und concordis. corculis, Jena, 1593.
} 
latino de Michael Faber que diseña un escudo de armas y está en la Herzog August Bibliothek de Wolfenbüttel.

Según Higgins (p. 49), en la Biblioteca Real de Kobenhavn (Suecia) se encuentra un caligrama en forma de copa o cáliz, en latín, compuesto por Anthonius Netenblad, e impreso por Henricus Ronzov para Nicolaus Uvegener en 1597.

Otro poema-cáliz, en holandés, aparece, según dice el mismo Dick Higgins (p. 95), en el Wonderbook (1542) de David Joris de Gand (ca. 1501-1629). El mismo crítico conjetura (p. 45) que un caligrama-altar que Carbonero y Sol atribuyó a Annardo Gamerio Moseo debió de publicarse en el raro volumen De merito Christi. An illud papistae suis concionibus, caeremoniis et sacris adhibuerint. ${ }^{54}$

Del polaco Daniel Naborowski (1573-1640) es un texto en prosa latina en forma de cáliz que, según Higgins (p. 132), aparece en un libro manuscrito de Daniel Cromer, fechado en 1593 y conservado en la Biblioteca PAN de Gdansk. Seis caligramas en latín se encuentran en Reverendissimo in Christo Patri et Dno. Francisco Lacki de Wawrzyniec Susliga (1570-1640): ${ }^{55}$ una mitra episcopal (f. B3r), una cruz pectoral (f. $\mathrm{C} 2 \mathrm{v}$ ), una cadena con tres cruces (f. C1r), un báculo y un anillo (f. C2r), un cáliz (f. B4v) y una columna (f. B2r).

\section{El Barroco}

Como ya he apuntado en la nota 3 , en el apartado de mi libro dedicado al caligrama barroco decía no conocer ninguno español de los siglos XVI y XVII, aunque sí otros artificios literarios más o menos próximos. Indagaciones posteriores me llevan a retirar lo dicho: desde 1977 hasta hoy he tenido noticia de dos. ${ }^{56}$ Conviene

\footnotetext{
$\overline{54}$ Ex officina Plantiniana, Antwerpiae, 1568.

55 Architypographia Regia et Ecclesiastica, Kraków, 1598.

${ }^{56}$ Debe estar bien claro que concedo al término caligrama el sentido estricto que le da la definición del $D R A E$, citada en la nota 1 , o la que yo mismo, para evitar confusiones, establecí al comienzo de mi libro: «Texto literario -en general poéticocuya disposición gráfica reproduce un objeto en él aludido»; definición que, por cierto, me parece más precisa que la académica, que viene a excluir de la categoría de caligrama los textos anteriores a la imprenta y los que representan no propiamente "el contenido" del texto, sino algún objeto relacionado de alguna manera con él. Consecuentemente, y lamentando mucho defraudar a quienes piensan que en un trabajo sobre caligramas ha de hablarse de otras formas de literatura visual,
} 
aclarar que en rigor no son caligramas puros, puesto que se sirven también del procedimiento del laberinto. Uno de esos dos technopaegnia es el aducido por Infantes en contra de mi afirmación. Se titula "Mundo de Eufrosina, Gracia del Oraculo de Apolo" y tiene la forma de un globo terráqueo, que, según su subtítulo, "empieça y acaba en su centro, siendo su centro, los estremos". Aparece en el Coro de las Musas dirigido Al Excelentissimo Señor Don Francisco de Melo, Cavallero de la Orden de Cristo, Comendador de S. Pedro de la Vega de Lila, y de S. Martin de Rañados, Señor de la Villa de Silvam, Alcayde Mayor, y Governador de la Ciudad de Lamego, Trinchante Mayor del Serenissimo Principe de Portugal, de su Consejo, y su Embaxador Extraordinario à la Magestad de la Gran Bretaña Carlos Segundo, etc. del Capitán don Miguel de Barrios. ${ }^{57} \mathrm{Si}$ esta composición es un caligrama y a la vez un laberinto, ${ }^{58}$ la otra, que he conocido gracias a Ana Hatherly ${ }^{59}$ y se encuentra en un manuscrito anónimo de la Biblioteca Geral da Universidade de Coimbra, es, a la vez que caligrama, laberinto y enigma. Corresponde a unas "décimas con finales enigmas" con el dibujo central de un sol antropomorfo y algunos otros elementos también dibujados. Del sol salen diez rayos anchos, pero de forma decreciente, en el interior de cada cual se inscriben unas palabras, y otros muchos rayos ya puramente lineales. Al extremo de cada rayo ancho hay dibujado un círculo mayor que el del propio sol, y en cada uno de estos círculos aparece representado un objeto: una mariposa junto a una vela, una rosa, el sol, una hermosa dama, una estrella, una candela, etc. Todo el conjunto está bordeado por una banda o cinta continua dentro de la que figuran más palabras, que completan las anteriores y el sentido de los dibujos enigmáticos. Lo aclararé con un par de ejemplos: en uno de los rayos se lee: "No contenta con su", y su extremo más agudo señala el dibujo de

no me ocupo aquí de cosas como acrósticos, mesósticos, laberintos, banderas, etc. a no ser que constituyan a la vez caligramas.

${ }^{57}$ Baltazar Vivien, Brusselas [Amsterdam], 1672, p. 642.

${ }^{58}$ El propio Barrios lo deja bien claro en las líneas que siguen a su poema visual: "El Laberinto deste Mundo, tiene por entrada à ROMA, como cabeça del Aguila de su imperio; y por salida al AMOR que todos le tienen hasta lo ultimo de la vida. Ocupan sus quatro partes las dos Monarchias Cristiana, y Mahometana, significadas en la Aguila de dos cabeças como publica esta octava que viene à folio 182 desde Libro", etc.

${ }^{59}$ A experiência..., fig. 79. 
la estrella, de modo que el verso ha de leerse: "No contenta con su estrella". Pero en la banda exterior dice, al otro lado de la estrella: "Corta luz es de una", con que ha de leerse: "Corta luz es de una estrella". En el siguiente rayo pone: "Ya la luz de su", y la punta del rayo indica la candela, en cuyo borde dice: "No produce tu". En este caso, entonces, los dos versos rezarían, respectivamente, "Ya la luz de su candela" y "No produce tu candela"... Como se ve, nos encontramos ante algo bastante más complicado que un mero caligrama.

El hallazgo de estos dos carmina figurata invalida -0 , más bien, obliga a matizar-mi afirmación (p. 47) de que el más antiguo caligrama español es "El miriñaque" de José Rodríguez, aparecido en el número 21 de La Aurora del Miño de Lugo el 18 de setiembre de 1857; afirmación que Rafael de Cózar refutó, a mi juicio infundadamente, en la p. 362 de su Poesía e imagen..., ${ }^{60}$ aduciendo la existencia de un "Poema en forma de cucurucho" publicado por Tomás Rodríguez Rubí en la revista madrileña El Alba el año 1838. Y digo infundadamente porque esta composición, que Cózar reproduce, no se atiene a la definición de caligrama que me sirve de referencia, ya que su texto no alude de ningún modo a un cucurucho ni a nada asociado a él, y constituye más bien una "escala métrica", modalidad de artificio de la que no faltan en España e Hispanoamérica los ejemplos románticos.

Ana Hatherly, en su obra ya citada, ofrece una novedosa e interesante información sobre $\tau \varepsilon \chi v o \pi \alpha i ́ \gamma v l \alpha$ barrocos portugueses. Uno en forma de cruz que copia, impreso en el libro de Joseph Pereira Velozo Desejos Piedosos de Huma alma Saudosa ${ }^{61}{ }^{6}$ es una sucesión de letras sin sentido, por lo que no debe considerarse plena y propiamente caligrama. ${ }^{62}$ Sí lo es otra cruz, ésta manuscrita y anónima, tomada por la misma estudiosa (fig. 88) de la Biblioteca Pública e Arquivo Distrital de Évora. Una cruz más, ésta con elementos dibujados y en latín, la toma Hatherly (fig. 91), conjeturándola del siglo XVII, de un $m s$. de la Biblioteca Geral da Universidade de Coimbra. En cada brazo se inscribe una palabra y en posición central dentro de un círculo se lee "MUNDVM".

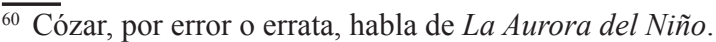

${ }^{61}$ Miguel Deslandes, Lisboa, 1688.

${ }^{62}$ A experiência..., fig. 4 de la antología final, sin paginar, del volumen.
} 
Tampoco es en rigor caligrama otro texto, éste en lengua portuguesa -aunque para Hatherly de autor posiblemente español-, que la estudiosa copia (fig. 32) de la obra manuscrita de Juan Lopes Cierra Panegírico Fúnebre, compuesta en San Salvador de Bahia de Todos os Santos posiblemente en el siglo XVII y guardada en la Biblioteca Nacional da Ajuda. Se presenta como "anagrama acrostico", y, de hecho, las primeras letras de cada línea forman el nombre del homenajeado: "Affonso Furtado". El texto, que está rodeado por una línea dibujada y acompañado de algunos otros elementos no textuales, se dispone en forma de piña decorativa, si bien en el $m s$. aparece denominado "tuba libitina", es decir "trompeta fúnebre". En la Biblioteca Geral da Universidade de Coimbra se conserva un soneto laberíntico manuscrito, dispuesto en forma de sol y con elementos dibujados, de Paschoal Ribeyro Coutinho, en elogio de Luis Nunez Tinoco. ${ }^{63}$ Allí se encuentra asimismo un texto latino, manuscrito y anónimo, que se organiza en forma de sol, pero con múltiples elementos dibujados que lo apartan del modelo del caligrama puro. ${ }^{64}$ También en el siglo XVII sitúa hipotéticamente Hatherly un caligrama en prosa portuguesa en forma de piña ornamental (fig. 85), cuyo autor es António Manoel Leyte Pacheco Malheiro e Mello, texto custodiado en la ya citada biblioteca universitaria de Coimbra; pero a mi entender tampoco se trata de un auténtico caligrama por ser puramente caprichosa y decorativa esa disposición, asociable, por otra parte, a una práctica corriente en la impresión de colofones, a la que hice referencia en la p. 27 de mi libro. Menos motivos todavía existen para considerar caligramas otros tres textos en latín, editados en la Isagoge del trinitario Frei Joâo Felix, ${ }^{65}$ que recoge también Hatherly (fig. 86 y 87): el primero tiene forma de rombo; los otros, que pudieran parecer sendas siringas, son en realidad -y así lo hace constar su autor en una anotación- poesías polimétricas de anchura creciente. La propia Hatherly incluye este tipo de textos en la categoría de "Escrita Ropálica" (del griego rhopalon "hacha"), "assim chamados por serem escritos de maneira que, visualmente, cresciam ou diminuíam de tal sorte que por fim formavam uma imagem

\footnotetext{
${ }^{63} \mathrm{Cf}$. Ana Hatherly, A experiência..., fig. 49.

${ }^{64} \mathrm{Cf}$. Ana Hatherly, A experiência..., fig. 80.

65 Off. de Pedro Craesbeck, Lisboa, 1613.
} 
parecida com uma clava ou uma maça", y los relaciona con las "escalas métricas" del XIX (p. 237).

Giovanni Pozzi, en su espléndido trabajo, ${ }^{66}$ recuerda cómo en las fiestas barrocas a veces se inscribían textos poéticos sobre las arquitecturas efímeras, y menciona una oda caligramática con la forma del "caballo heráldico" de la casa de Osuna, inscrita en el monumento erigido en el Munusculum de los jesuítas de Nápoles en honor del Virrey don Pedro Téllez Girón, Duque ${ }^{67}$ de Osuna; oda recogida, aunque ya sin la disposición gráfica original, en Carminum libri quatuor Ossuniensium duci collegii neapolitani $S$. I. munusculum, laudationem continens qua a patribus eiusdem societatis exceptus est (Napoli, Biblioteca Nazionale, ms. "IX F 43"). El Theatrum temporaneum aeternitati Caesaris Monti [...] sacrum de O. Boldoni ${ }^{68}$ describe-como Pozzi indica también en el primero de los lugares citados- los “apparati” erigidos en Sant' Alessandro de Milán con ocasión de la entrada del cardenal C. Monti: en la puerta se pintó un grupo de pastores músicos y cantores; encima de ellos se inscribió un epigrama relativo a esa pintura; debajo, un poema en forma de zampoña o siringa. Durante la fiesta, un grupo de escolares vestidos de pastores cantaban el texto de este carmen figuratum. Alude asimismo Pozzi ${ }^{69}$ a un poema de G. B. Marino, también en forma de zampoña, que, escrito para ser igualmente expuesto en grandes dimensiones, al tener que ser reducido para su impresión en un libro, pierde su disposición caligramática.

El mismo estudioso hace referencia ${ }^{70}$ a un volumen editado en 1616, con ocasión de la partida de Nápoles del Virrey D. Pedro Fernández, Conde de Lemos, por los jesuítas de la ciudad (recopilación paralela a la ya considerada de homenaje al Duque de Osuna): Carminum libri quattuor discessuro Lemensium comiti collegii neapolitani S. I. munusculum laudationem continens qua a patribus eiusdem societatis exceptus est. ${ }^{71}$ Además de epigramas y anagramas, el libro contiene (p.70-76) un texto de intención caligramática que debería representar la fachada de una iglesia, con

\footnotetext{
$\overline{{ }^{66}}$ La parola..., p. 64-65 y 121-122.

${ }^{67}$ Que no Conde, como Pozzi dice una vez (p. 64), por evidente lapsus.

${ }^{68}$ Apud haeredes P. Pontii, Mediolani, 1636.

${ }^{69}$ La parola..., p. 65.

${ }^{70}$ La parola ..., p. 227.

${ }^{71}$ Typographia Tarquinii Longi, Neapoli, 1616.
} 
el altar en el medio, aunque los tipógrafos no lograron conservar el perfil deseado, y otro (p. 77-80) que figuraba un campamento militar con sus torres, sus banderas, etc. ${ }^{72}$

El propio Pozzi cita (p. 226) un $\tau \varepsilon \chi v o \pi \alpha i ́ v v l o v$ en forma de huevo, rodeado de un acróstico, que figura en la Gemmea corolla adamantalis, saphyrulis smaragduslique contexta, recopilación hecha por Antonio Bernardo ${ }^{73}$ de composiciones de alumnos del Seminario Patriarcale de Venecia, y otro (p. 229) que dibuja dos columnas, publicado por el jesuíta matemático Marco Bettini en Lycaeum e moralibus, politicis ac poeticis. Lycaei pars tertia seu viridarium, in quo per eutrapelias sive urbanitates poeticas virtus feriatur $^{74}$ (p. 48-49) con motivo de la "laurea" doctoral de Ottavio Farnese. No me parece, en cambio, caligrama propiamente dicho, puesto que la forma de corazón ${ }^{75}$ le viene dada más por las líneas dibujadas que por la disposición del texto, un poema visual del sacerdote portugués Andrea Bayan, que Pozzi reproduce y comenta (p. 126-127 y 230), con versos concatenados y acrósticos, editado en la obra de Patrizio Fattori Ampla ed diligente relazione de gli onori fatti al cuore di san Carlo, per lettera scritta all 'ill. [...] Carlo Borromeo, nipote del santo dal r. s. Patrizio Fattori di Torrita [...] data in pubblico da me infrascritto con l'aggiunta della figura in principio e del cuore con la sua dichiarazione in fine. ${ }^{76}$

En mi libro, apoyándome en el trabajo de Margaret Church, hice referencia (p. 39 y 40) a la producción caligramática de Baldassarre Bonifacio, recogida en sus Musarum libri XXV. Gracias a Pozzi (p. 214-224) puedo ampliar ahora la información: este libro se publicó en Venecia en $1628^{77}$, y en su comienzo encontramos ya un dibujo que representa la rueda del blasón de la familia de Domenico Molin, mecenas del poeta, dentro de la cual se inscriben otros 16 dibujos más pequeños, de diversos objetos. Sobre cada uno de éstos seguirá un caligrama: una torre (con acróstico y mesóstico), un escudo, una columna, las sandalias aladas de

\footnotetext{
${ }_{72}$ Higgins, Pattern Poetry..., p. 45, sostiene que se trata de unas columnas y un altar.

73 Typographia Varisciana, [Venezia], 1621.

74 Apud Evangelistam Deuchinum, Venetiis, 1626.

${ }^{75}$ Más exactamente, del corazón de San Carlos Borromeo, que había sido trasladado a Roma con gran solemnidad.

${ }_{76}$ Bartolomei Zannetti, Roma, 1614.

77 Apud Antonium Pinellum.
} 
Mercurio, una clepsidra, un huso, un órgano, un hacha, una escalera, un corazón, un trípode, una caracola, un sombrero, una palma o pluma, un rastrillo, un ánfora, un cáliz, un cubo, una sierra y un ara. En todos ellos el texto va rodeado de líneas dibujadas, y en algunos hay además otros elementos gráficos, de modo que no se trata de caligramas en estado puro. Higgins (p. 39-41) ofrece más información y reproduce cuatro de esos carmina figurata.

Tampoco dejé de referirme en mi estudio a Fortunius Licetus (p. 31, 38-39), ${ }^{78}$ pero a los technopaegnia por él recogidos o creados que mencioné habría que agregar los poemas con forma de alas, altar y hacha, que cita Pozzi (p. 224), publicados en las p. 135-137 de su volumen L'eroica ed incomparabile amicizia degl'illustrissimi signori N. Barbarigo e M. Trevisano [...] celebrata con diverse maniere di poesie. ${ }^{79}$ Por otra parte, y sin dejar a Fortunius Licetus, en mi libro dije (p. 39) que L. Portier juzgaba inencontrable la obra de aquél Imitationes figurati metri a Simmia Rhodio inventi. ${ }^{80}$ No obstante, Pozzi sí parece haber dado con ella, ya que afirma (p. 224) que contiene textos con las formas tradicionales de huevo, zampoña, alas, hacha y altar y que alternan el latín y la lengua vulgar.

En la Miscella elogiorum, acclamationum, adlocutionum, conclamationum, epitaphiorum et incriptionum de Lorenzo Pignoria (1571-1631), ${ }^{81}$ que yo había citado también (p. 38), pero sólo por las composiciones de Fortunius Licetus allí recogidas, señala igualmente Pozzi (p. 226) la presencia de otros caligramas cuya disposición dibuja (p. 91-103) un altar, una cruz, dos pirámides y un ánfora ${ }^{82}$ y en los preliminares del poema de Ferdinando Donno L'allegro giorno veneto over Lo sponsalizio del mare ${ }^{83}$ un texto en forma de pirámide del bresciano Domizio Bombarda (f. 5r). Pozzi menciona asimismo (p. 130-131) la obra de Eugenio di San

\footnotetext{
${ }^{78}$ Queriendo restituir a la lengua vulgar este nombre latinizado con que firmaba sus libros, lo llamé "Fortunio Liceto", lo cual fue una inexactitud, ya que, según he podido comprobar después de publicado mi libro, su apellido era Liceti.

${ }^{79}$ Venezia, 1628.

${ }^{80}$ Apud Gasparem Crivellarium, Patavii, 1627.

${ }^{81}$ Impressores Camerales, Patavii, s.a. [1626].

${ }^{82}$ Higgins, Pattern Poetry..., p. 51, añade un rombo (p. 85) y dos copas (p. 100 y 102), aparte algunos finales de texto o colofones en forma decreciente.

${ }^{83}$ Sarzina, Venezia, s. a.
} 
Giuseppe CastrVM DoLorIs et honorIs sive mausoleum poeticum Mausolo austriaco Ferdinando tertio, augustissimae Arthemissiae imperatricis Eleonorae coniugi in Parnasso extructum, ${ }^{84}$ homenaje fúnebre a Fernando III, donde puede verse (f. T2r) una pirámide con elementos diujados, que es a la vez acróstico y teléstico. Higgins (p. 51) añade, no sé con qué fundamento, que en ella hay también una bandera y una cruz, aunque dice que no pudo consultar el texto.

A un autor alemán pero residente en Nápoles, Michael Kelner, se debe -según nos dice también Giovanni Pozzi (p. 65 y 228)- la Epaenodia ad [...] Petrum Giron ducem Ossunae [...] quam accivit Michael Kelner germanus ubius, ${ }^{85}$ donde aparecen una poesía-pirámide -que, por exigencias del formato, se parte en dos trozos (p. 25-26)-, otro texto que trata de representar nada menos que el universo - con un acróstico interior, además- (p. 22-23) y un arco triunfal igualmente con acróstico (p. 30-31). Los tres pueden verse reproducidos en el libro de Pozzi (p. 64, 104 y 105), a quien le «incuriosisce l'omonimia che corre fra lui e il dedicatario di uno dei più belli e antichi carmi figurati tedeschi, il cuore nuziale omaggiato a C. Kelner nel 1587 » (p. 228), aunque admite que puede tratarse de una pura casualidad.

En el contexto del Barroco alemán, indicaré que Enoch Hanmann, en sus Anmerckungen In die Teutsche Prosodie, ${ }^{86}$ afirma que los caligramas más corrientes son huevos y copas ( $\mathrm{p}$. 290), y reproduce algunos en forma de pirámide (p. 291), huevo (p. 353), pirámide o plinto (p. 354-355), cruz (p. 356) y copa (p. 357), tomados todos salvo el primero del volumen de Justus Georg Schottel que cité en la p. 33 de mi estudio. Y también Daniel Georg Morhof (1639-1691) se ocupa de los $\tau \varepsilon \chi v o \pi \alpha i ́ \gamma v i \alpha$ en su libro Unterricht von der teutschen Sprache. ${ }^{87}$

Pozzi menciona o copia en el suyo (p. 107, 108, 122, 129) un buen número de caligramas barrocos en lengua alemana para mí antes desconocidos: un poema-estrella (con los bordes dibu-

\footnotetext{
$\overline{{ }^{84} \text { Matthei Cosmerovii, Viennae, } 1657 .}$

${ }^{85}$ Tarquinius Longus, Neapoli, 1620.

${ }^{86}$ Cf. Martin Opitz, Prosodia germanica, Oder Buch von der Deudschen Poeterey, Christian Klein, Frankfurt am Mäyn, 1658, obra de la que es apéndice la de Hanmann.

${ }^{87}$ J. Wiedemeyers, Lübeck, 1700.
} 
jados), otro en forma de sol, también con parte dibujada, y otros muchos, con acrósticos incorporados ${ }^{88}$ del libro de Hermannus a Santa Barbara titulado Carmelo-Parnassus in xenium oblatus [...] d. Ioanni Gualterio Slussio; ${ }^{89}$ un poema-fortaleza del suizo H. R. Wirtzen, ${ }^{90}$ y una copa (que, además, contiene en su interior una cruz) de D. Gessner, impresa en el libro colectivo Haussteurliche Vers-Geschenke aus das Hochzeitliche Freuden-Fäste des [...] Hr. Hans Ulrich Holtzhalben [...] (1676), ${ }^{91}$ donde figura también otro caligrama nupcial en forma de copa de F. Weiss, ${ }^{92}$ del que hay ejemplar en la Zürich Zentralbibliothek. El estudioso italiano copia además (p. 123) uno incluído en la obra de L. De Gand de Brachey Sol britannicus regi consecratus, cuyo texto configura un sol, pero con elementos dibujados.

Gracias a los libros de Giovanni Pozzi y Rafael de Cózar tuve las primeras noticias de la existencia del tratado Pöesis Artificiosa ${ }^{93}$ del carmelita F. Paschasius, quien, además de afirmar que existen caligramas (a los que llama "poemas centaurinos") con formas geométricas, de huevo, de pirámide, de cruz, de ángel, etc. ${ }^{94}$ recoge varios de su propia cosecha: dos conos -así lo proclaman los respectivos títulos, aunque en rigor más parecen huevos- (p. 146, 147), tres pirámides (p. 148, 148, 150), dos cruces (p. 149, 209) y un sol (p. 154). ${ }^{95}$ La pirámide de la p. $150 \mathrm{y}$ el sol los reproduce en su estudio Pozzi (p. 125 y 137 respectivamente), pero aclarando que el autor es Paschasius a S. Iohanne Evangelista (Pascasio di S. Giovanni en italiano) y el título completo de la obra Poesis artificiosa, cum sibi praefixa perfacile manductione ad Parnassum, tam veterum quam recentiorum poetarum authoritate studiose iuventutis proposita labore et studio [...] ${ }^{96}$ (Los datos de Pozzi

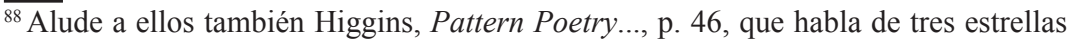
y dos soles.

${ }^{89}$ Apud Arnoldum Bronckart, Leodii, 1687.

${ }^{90}$ La parola..., p. 122.

${ }^{91}$ La parola..., p. 103.

${ }^{92}$ La parola..., p. 129.

${ }^{93}$ J. Petri Zubrodt, Herbipoli, 1674 [aunque de las referencias de Cózar se desprende que hubo una edición en 1668].

${ }^{94}$ Cf. Rafael de Cózar, Poesía e imagen..., p. 298 y 455.

${ }^{95}$ Los de Paschasius y otros copiados por éste los reproduce Cózar, Poesía e imagen..., p. 291-300, 455, 562, 563, 564 y 565 .

${ }^{96}$ Sumptibus Johannis Petri Zubrodt, typis Eliae Michaelis Zinck, Herbipoli, 1674.
} 
suelen ser más exactos que los de Cózar). El libro de aquél agrega,

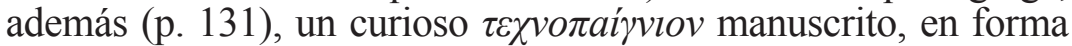
de rosa, que aparecía en la p. 151 de Poesis artificiosa y Cózar parece no haber advertido.

Jeremy Adler cita y reproduce en su trabajo de $1982^{97}$ un textocruz en prosa latina, con una orla tipográfica alrededor, publicado por Johannes Maukisch en Christliche Leich-Predigt, sermón fúnebre de Maria Höpfner ${ }^{98}$ (f. L4r). El mismo estudioso nota (p. 118-119) la presencia de un poema-corazón atravesado por una cruz, y (p. 121) de dos himnos en forma también de cruz -acompañados de la correspondiente notación musical-, en Sieben Theile wohlriechender Lebens-Früchte, de George Weber. ${ }^{99}$ En este libro figuran, además, según nos hace saber Higgins (p. 83), estrellas (p. 2), una torre de ajedrez (p. 58), cinco corazones con música (59-64), seis alas (p. 190-191), otros seis corazones (p. 216-221), un ara (p. 242), siete rombos con notación musical (p. 274-279), una hostia y un cáliz (p. 306, 315), una serie de monumentos (p. 364-366), otro altar (p. 370), una serie de cuatro altares o monumentos con música (p. 430-435) y una cruz con una bandera. Adler cita y copia, además (p. 133-134), otro caligrama-cruz, en alemán, editado en los Geistliche Sonnette, Lieder und Gedichte (p. 403) de Catharina Regina von Greiffenberg (1633-1694); ${ }^{100}$ también (p. 121-122) un "monumento" con forma de corazón, con un marco asimismo de texto en torno, que se imprimió en Saluberrima et Necessaria, sermón fúnebre anónimo en honor de Ursula Catharina Dietz; ${ }^{101}$ recoge igualmente (p. 117) un poema en forma de copa que se encuentra en una Comoedia incluída en el volumen Hanauische Lob-Lieb-Lust-Lehr-und Leid-Gedichte de Quirinus Moscherosch (1623-post 1657) ${ }^{102}$-autor también, según Higgins (p. 80) de otra copa (p. 16), una cruz (p. 81) y un pañuelo que es a la vezun laberinto (p. 64)-; otro (p. 118) dispuesto con la figura de unas andas con un ataúd encima, compuesto por Christian Wagener para el funeral de

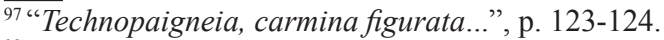

${ }^{98}$ Leipzig, 1641.

${ }^{99}$ Danzig, 1649, p. 164 y 336-342, respectivamente.

${ }^{100}$ Bayreuth, 1662. Lo reproduce también Higgins, Pattern Poetry..., p. 75.

${ }^{101}$ Coburg, 1667, f. 1r.

${ }^{102}$ Estrasburgo, 1668, p. 50.
} 
Ludwig Meier, Moesta cupressus, ${ }^{103}$ y una cruz en alemán (p. 124125), hecha por Valentin Bernhard en el Christliche Leichpredigt, sermón fúnebre de Johann Ludwig Einsiedel, ${ }^{104}$ que, según Dick Higgins (p. 83), se conserva en la Colección Stolberg de oraciones fúnebres de la Herzog August Bibliothek de Wolfenbüttel. El propio Adler observa, ${ }^{105}$ confirmando algo que yo había señalado ya en mi libro (p. 36-37), que en el siglo XVII, y de modo especial en Alemania, suelen editarse caligramas en forma de corazón y copa con ocasión de las bodas, y en forma de pirámide y catafalco para los funerales. Al XVII conjetura Adler que corresponde también una composición anónima en latín, "Arma Christi", conservada en la Bayerische Staatsbibliothek de Munich, que sobre un fondo de texto dispone un acróstico y varios dibujos que figuran las tres cruces del Calvario y los instrumentos de la Pasión, todo con textos inscritos. El dibujo que representa la escalera, por ejemplo, tiene entre los peldaños, colocadas verticalmente, las letras $S C A L$ $A$. El estudioso ve en este carmen figuratum una imitación de los de Rabano Mauro. ${ }^{106}$

Dick Higgins enumera en su documentadísimo libro (p. 71 84 y 138-146) una larga serie de caligramas alemanes del XVII que me eran desconocidos en 1977. En su mayoría proceden de la Herzog August Bibliothek de Wolfenbüttel. Bastantes de ellos fueron compuestos e impresos con motivo de bodas, y prueban lo fundado de la opinión de Adler recogida en el párrafo anterior. El enlace de G. Alardus y Anna Laurenberg, celebrado en Lübeck en 1616, se conmemoró con un poema-copa en latín, debido a Johannes Albinus. Otra copa en latín, ésta de Laurentius Ledanius, se estampó en el folleto Hymenaei in honorem nuptiarum cuando en 1620 se casaron Wakter Lyndsay y su novia Barbara. Para otra boda compuso Paul Haugsdorf una copa en alemán, incluída en el folleto Spirituale poculum nuptiale, den christlichen HochzeitGästen [...] eingeschenckt. ${ }^{107}$ Con ocasión de la de Christian Lorentz y Johanna Becker, el 23 de setiembre de 1633, se imprimió

\footnotetext{
$\overline{{ }^{103} \text { Halle, } 1669, \text { f. 6v. }}$

${ }^{104}$ Rudolfstadt, 1670.

105 “Technopaigneia, carmina figurata...,", p. 118.

106 “Technopaigneia, carmina figurata...,", p. 123.

${ }^{107}$ Joachim Clemens, Zittaw, 1621.
} 
un folleto en el que aparece una copa más en latín, cuyo autor fue Johann Lehnmann. Está en la Herzog August Bibliothek. Para el enlace de Ulrich Schozamens y Margareth-Elisabeth Steobanin, en 1641, se editó otro caligrama en forma de copa o cáliz, compuesto por David Wilcken. Johann Friedrich Glaser hizo otro semejante para el matrimonio de Gottfried Müller y Margaretha Haberland el 30 de noviembre de aquel mismo 1641, estampado en Braunschweig por un editor desconocido. Hay un ejemplar en la Herzog August Bibliothek. Para el casamiento de Christian August Mithobius y Anna Sophia Wolf se imprimió otra copa o cáliz, en latín, el 14 de octubre de 1645. Puede verse en la Herzog August Bibliothek de Wolfenbüttel. En la Biblioteca Real de Estocolmo se conserva una semejante, de Ignatius Meurer, impresa en 1646 para el enlace matrimonial de Heinrich Trips y Johanna de Geere. Otra se debe a Ludolff von Lude, que la hizo para la boda de Melchior Johann Türcken y Anna Catharina Wölder el 6 de febrero de 1649. Fue editada en Hannover por Johann Friedrich Glaser y está en la Herzog August Bibliothek de Wolfenbüttel. Para el casamiento de August Wieg y Clara Elisabeth Hagen el 13 de abril de 1650 hizo otro texto análogo - pero éste en prosa- Christian Scharmidt. Hay un ejemplar en la Herzog August Bibliothek. Joachim Rosencrantz hizo otro caligrama nupcial en forma de copa para ofrecérselo a Johann Haldenschleben y Catherine Künnen el 27 de enero de 1651. No tiene datos del impresor ni el lugar, y se encuentra también en la biblioteca de Wolfenbüttel. Otro poema-copa compuso Martinus Ignatius von Döring, titulándolo Scherz und Wunsch Pocal, con ocasión del enlace de Hieronymus von Laffert y Richel Dorothea Stöterogg, el 28 de enero de 1656 . Un ejemplar se conserva en la Herzog August Bibliothek de Wolfenbüttel. Otro semejante fue hecho por Quirin Capsius para la boda, el 19 de febrero de 1661, en Stassfurth, de Wolf-Thilo von Trotha y Anna von Hakeborn. Lo imprimió Johann Ockell en Quedlinburg. En 1665 se publica en Rudolfstadt otra copa de celebración matrimonial, ésta debida a Volckmar Happe y dedicada a Albrecht Anton, Conde de Schwarzburg y Hahnstein, y Aemilia Juliana, Condesa de Barby y Nuehlingen, que se casaron el 7 de junio de aquel año. Otro caligrama del mismo tipo, anónimo, fue estampado por Hermann Brauer en 1666 para la boda de Focko Krumming y Kunigunde 
Zobel y se conserva en la biblioteca de la Universidad de Bremen. Otro poema-copa anónimo, en latín, recordó el matrimonio, en 1669 , de Dithmar Wachmann y Margarethe Köper. Se conserva en la biblioteca universitaria de Bremen. La misma biblioteca guarda otro análogo, éste de 1681, dedicado al enlace de Dietrich Bönning y Margarethe Elisabeth von der Lieth. A J. Walmann se atribuye otra copa nupcial en latín, dedicada a Henricus Edzards y Anna Abrahams, impresa por Hermann Brauer en 1687 y conservada en la biblioteca de la Universidad de Bremen. A Christoph Schabeloek se debe otro poema-copa, éste destinado a la boda de Paul Wividts [?] y Dorothea Sophia Kruger en 1688. Un caligrama nupcial más en forma de cáliz o copa, en latín, es el impreso en Breslau para Adamus Kruberus y Anna Magdalena Hermania en Ebenezer mnemonico-eucharistico-eugmaticus [...] in nuptiis Adami Kruberi [...]. ${ }^{108}$ Otro de fecha ignorada pero del siglo XVII, escrito para Andreas Fridzberg, se encuentra en la biblioteca de la Universidad de Abo, en Finlandia. Otro, también de fecha imprecisa dentro del siglo XVII, es el dedicado por Christopher Hipsted, en latín, a Johann Georg Zepper y Gesche Spekhan, que está en la biblioteca universitaria de Bremen. Otro poemacopa conmemora el matrimonio de Zacharias Beichling y Maria Siegfried, celebrado el 20 de febrero de un año no especificado. Hay un ejemplar en la Herzog August Bibliothek de Wolfenbüttel. Uno más es el compuesto por Christoph Chapmeyer para el enlace de cierto señor Kronner.

En otras ocasiones las bodas se celebraban con caligramas en forma de un par de corazones. Para la de Nicolaus Petrus Riaelius y Catharina Alm, compuso el correspondiente technopaegnion en 1657 Nic[¿olaus?] Laur[¿entius?] Tolfstadius, probablemente de Estocolmo. Con ocasión de la de Wilhelm Mumm y Maria Eleonora Tauscherin, en 1674, Nic. Wankijff, impresor real en Estocolmo, editó uno similar, de autor anónimo. Otros dos corazones hizo alguien que firma "Christello" para el matrimonio Rosenau-Wende el 4 de octubre de 1698. Se imprimió sin datos, y hay un ejemplar en la Herzog August Bibliothek de Wolfenbüttel. Un corazón solo, en latín, debido a Joachim Jordan, que se recoge

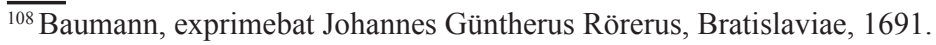


en un folleto titulado Epithalamia in honorem [...] Christophori Butelli, conmemoró la boda de Christoph Butel en 1602. ${ }^{109}$

Para la de Christian Schwartzen y Regina Volscovia se tiró en 1606 un poema-laúd en latín. Para la de Joh. Ad. Braun y Barbara Baur se editó en Estrasburgo, en 1607, en el taller de Jodocus Martinus, una hoja con un poema-urna en latín de Wend. Mart. Gerlach, del que hay un ejemplar en el Museo Gutenberg de Mainz. Para la de Joachim Senge y su novia Catherina se imprimió en 1613 un poema-altar, anónimo, en latín, en el que cada verso es, además, un palíndromo. Con motivo del enlace de David Schröder y Anna Lyggefels, que tuvo lugar en Berlín en 1619, Laurentius Kilchius hizo otro poema en latín en forma de jarra de cerveza. El de Christoph Philipp Richter y Catharina Heinz, celebrado en Hannover el 4 de junio de 1627, se conmemoró con un poema-diamante en latín, probablemente obra de Johann Christian Dienstorffer, impreso por la viuda de Weidner en un folleto de poesías escritas para la ocasión, del que hay ejemplar en la Herzog August Bibliothek. El casamiento de Volrath Eisentraut y Margarethe Sauerhering el 6 de mayo de 1649 dio pie a Heinrich Georg Kulenschmiedt para componer otro poema conmemorativo, éste en alemán, en forma de diamante, de cuyo impresor y fecha no hay constancia, pero que se guarda en la Herzog August Bibliothek de Wolfenbüttel. Si los datos de Higgins (p. 82) no son falsos, este mismo acontecimiento suscitó otro caligrama, éste con figura de árbol, obra de la pluma de Johann Schmied y publicado en Schöningen por un editor desconocido. Se encuentra, siempre según Higgins, en la Herzog August Bibliothek, donde tiene la misma signatura que el impreso anterior. En los años centrales del siglo XVII sitúa Higgins (p. 144145) dos technopaegnia nupciales, destinados a la boda de Andreas Runge y Anna Hesehusen, que atribuye a Peter Forstenovius, ambos bastante originales y relacionados con la Música: uno es un trombón en latín y el otro un laúd en griego, pero los dos con algunos elementos dibujados. ${ }^{110}$ De 1667 es otro caligrama de boda con forma de vela compuesto por Joachim Duncker para Joachim Fabricius y su novia Dorothea Sophia. En 1694 aparece un caligrama con un par de manzanas, escrito por Jacob Rothut

$\overline{{ }^{109} \text { Typ. Rethianis, Alten Stettin, } 1602 .}$

110 Epithalamia in gaudiis nuptiarum Dn. Andreae Rungii. 
para el casamiento de de Christopher Kauffmann y cierta señorita Busch. Puede verse en la Commerzbibliothek de Hamburgo.

Los funerales se conmemoraban en la Alemania barroca con caligramas en forma de ataúd, corazón, pirámide, copa, columna o cruz. Joachim Gössel imprimió una cruz en latín para las honras fúnebres de Joachim Middendorff, muerto el 17 de mayo de 1619. Se conserva en la Herzog August Bibliothek de Wolfenbüttel. Allí mismo se guarda otro caligrama fúnebre en latín, éste en forma de siringa, compuesto por Samuel Gloner en memoria de Johann Friedrich Benz. También allí figura un texto con forma de columna, dedicado hacia 1640 a la memoria de Christoph Anthon Victor, obra de Adolf Theobald Overbeck. Con un corazón se conmemoró en 1647 la del sueco Frederich Peringer. Uno con perfil de copa y otro de pirámide, debidos a Friedrich Hildebrand, aparecen en la hoja conmemorativa de Magdalena Otto, fallecida el 14 de marzo de 1652, que editó el impresor Hynitzsch en Northausen y se encuentra en la Herzog August Bibliothek. Otra pirámide de $\mathrm{C}$ [hristian] $\mathrm{H}$ [eise], de editor y ciudad desconocidos, recordó el funeral de Ursula von Heimburg, fallecida en Göttenstadt el 3 de octubre de 1659. Hay un ejemplar en la misma Herzog August Bibliothek. La muerte de Balthasar Olffen, en Braunschweig, dio pie a Friedrich Wigand para escribir un caligrama en forma de columna o altar, impreso sin datos, pero hacia 1660. Se encuentra un ejemplar en la Herzog August Bibliothek. Forma de pirámide tiene el texto redactado por Johannes Parpard para el funeral de David Schröder, estampado por Johannes Hacken en Wittenberg el año 1661. Hartwig von Sprekelsen conmemoró con otra pirámide -que puede verse también en la Herzog August Bibliothek- el funeral de Nicholaus Daniel Steman, muerto el 13 de agosto de 1666. Otro texto en forma de ataúd se imprimió en 1669, para el funeral de Anna Sophia von Hackenborn, fallecida el 31 de octubre. Su autor es Bartholomaeus Runge y se editó en Quedlinburg, aunque el nombre del impresor no consta. Hay un ejemplar en la ya muchas veces citada biblioteca de Wolfenbüttel. Otra columna se hizo en Rostock en 1671 con motivo de las exequias del profesor y poeta J. Fabricius. Para las de Dorothea Christina Bote, cuyo fallecimiento se produjo el 20 de abril de 1675, Andreas Sander hizo un textocruz conservado en la Herzog August Bibliothek. Aquel mismo 
año el impresor Ludwig Röder estampó en Colberg otro carmen figuratum fúnebre en forma de cruz, debido a Daniel Simon, con motivo de la muerte del padre de éste, también Daniel Simon. En memoria de Catharina Clasen, muerta el 7 de enero de 1677 en Magdeburg, Alexander Christian von Syborg compuso un poemacruz que está en la biblioteca Herzog August de Wolfenbüttel. Para las honras fúnebres del profesor Hermann Conring, en 1679, se editó un poema-pirámide. Otro hizo Joseph Johann Becker, el mismo 1679, para las de Rudolph August de Braunschwig. Heinrich Christoph von Damm compuso un texto dispuesto en forma de corazón para el funeral de su padre, Georg von Damm, muerto el 15 de mayo de 1670. Lo imprimió C. F. Zilliger y hay un ejemplar en la Herzog August Bibliothek. Un globo anónimo en latín fue editado por Hermann Brauer con ocasión del funeral de Fernando Alberto I de Bremen en 1682. De 1684 es el poemacolumna dedicado por el impresor Johann Günther Roerer (o Rörer) a Christoph Albrechten en Danck-und-Gedächtnüss-Säule Herrn Christoph Albrechten. ${ }^{111}$ La misma fecha tiene otra copa incluída en la Centuria funebris de Tomas Höflich. En 1685 se estampa un Klag-Eich ("Roble de duelo") hecho por Johann Elias Kirch (1643-1723) para las exequias de Johann Hartlaub (16251684), alcalde de Schweinfurt. Se encuentra en la Bayerische Staatsbibliothek de München. En 1686 se edita otro texto fúnebre en forma de columna que Johann Philipp Härpffer compuso para Anna Elisabeth Groppe, muerta en Schweinfurth el 30 de abril. El impreso está en la Herzog August Bibliothek de Wolfenbüttel. Higgins menciona también (p. 82) otro texto en forma de cruz, guardado en la misma Herzog August Bibliothek, hecho por Johann Georg Schütz para el funeral de un señor Brunneman, impreso sin datos de editor, lugar ni fecha. Con un molino y un puente, conservados en la biblioteca de la Universidad de Bremen, se conmemoró en un año de la década de 1680 el funeral de Albert Löning.

En su importante aportación al conocimiento del caligrama barroco alemán, Higgins alude además a uno en forma de ara del checo Pavel Gisbicius, impreso en Schediasmatum farrago nova, ${ }^{112}$

$\overline{111}$ Baumann, Breslau, 1684.

${ }^{112}$ Christophorus Guyotius, Luguni Batavorum, 1602. 
y a otro del mismo autor - una pirámide invertida y truncada-, editado en Venceslai Rokycansky feriarum poeticarum. ${ }^{113}$ Hay otro caligrama en forma de copa en Propemticon [...] Zacchariae Brunsvicio Pardubiceno Praga ${ }^{114}$ de Martinus Rhacopaeus. Otra copa más puede verse en Amplissimis praestantissimisque viris consuli et senatoribus [...] civitatis Maioris Strezelicii [...] parsimoniae encomium de Esaias Vochius. ${ }^{115}$ Uno texto con silueta de vaso griego, con mesóstico, se recoge en el anónimo Viro reverendo et clarissimo Domino M. Christophoro Betulio ${ }^{116}$ (f. A4v). Cita también Higgins (p. 148) un huevo, a semejanza del de Simmias el Rodio, escrito en latín por Jan Haidelius, que lo imprimió en Musa illustrissimi [...] principi [...] Caroli ${ }^{117}\left(\mathrm{n}^{\mathrm{o}}\right.$ 20). En la obra de Nicolaus Spissius titulada Ampliss. inclitae Cuttebergae senatui [...] metallicae rei encomium ${ }^{118}$ puede verse otra copa o cáliz de Eliás Nysselus. Pavel Nemcansky recoge, en Vota strennae loco anno missa, ${ }^{119}$ un ancla con mesóstico dedicada a Matthias Konecny y dos copas, dedicadas a Matthias Cyrus y Georgius Erastus respectivamente. Un año más tarde aparece, en Chairosyné anamnésis praestantissimae [...] corona amplissimi senatus Bohemobrodensis [...] 27 aprilis anno 1616 feliciter renovati gratitudinis et honris ergo conscripta et dedicata de Zikmund Podkostelsky, ${ }^{120}$ un jarrón o ánfora de Johannes Nigrinus. Menciona asimismo Higgins (p. 147) un caligrama en prosa alemana con forma de laberinto ${ }^{121}$ que se encuentra en un folleto de 1620 conservado en la Bayerische Staatsbibliothek de Munich, y en una hoja suelta guardada en la Biblioteca del Museo Nacional de Praga. Menciona asimismo el estudioso citado los caligramas de diversos autores publicados en la Encyclopaedia septem tomis

\footnotetext{
$\overline{{ }^{113} \text { Christian Bergen, Dresden, } 1609 .}$

${ }^{114}$ Officina typogr. Schumaniana, Praha, 1606.

${ }^{115}$ Paulus Sessius, Praha, 1607.

${ }^{116}$ Typ. Rhetianis, Alten Stettin, 1607.

${ }^{117}$ Daniel Sedesanus, Praha, 1607.

${ }^{118}$ P[avel] S [ilesius], Praha, 1607.

${ }^{119}$ Samuel Adam a Veleslawina, Praha, 1615.

${ }^{120}$ Matthias Pardubicenus, Praha, 1616.

${ }^{121}$ Quizá no sea enteramente ocioso recordar que una cosa es un "laberinto poético" -composición, no necesariamente caligramática, cuyo texto requiere ser leído en un sentido distinto del normal-y otra un caligrama en forma de laberinto, como éste y otros.
} 
distincta de I. H. Alsted, Alstedius: ${ }^{122}$ una copa (vol. IV, p. 562), un huevo (vol. IV, p. 564) y un hacha (vol. IV, p. 566) anónimos. Hay un caligrama en latín, a la vez palíndromo, que representa un cetro y una mitra, impreso en 1623 (que se reimprimiría en 1753). En los comienzos del siglo XVII sitúa Higgins (p. 38) otro carmen figuratum anónimo en forma de cáliz. Otro texto anónimo, de gran formato, con el perfil de un ciervo, se publicó en 1625. G. Lemens compuso, según Pozzi (p. 125), otro poema-copa, que se encuentra en un manuscrito latino, inédito, de la Bayerischer Staastsbibliothek de Munich. Dos corazones en latín, con sus traducciones alemanas, hizo Christopher Lorenz von Halberstad para felicitar el año 1630 a Friedrich, heredero de Noruega y Duque de Braunschweig, y su esposa, la Duquesa Sophie-Elisabeth de Mecklenburg. Los imprimió Stern en Wolfenbüttel, y están en la Biblioteca Strahov de Praga. Para felicitar a los mismos destinatarios el año 1666 compondrían otro poema-corazón, impreso en Wolfenbüttel por el mismo Stern, Johann Georg Lipp y Johann Rochow. Puede encontrarse un ejemplar en la Herzog August Bibliothek. Samuel Pomario, sobre cuya existencia real expresa Pozzi (p. 127) algunas dudas, parece haber sido el autor de una hoja, impresa en Nürnberg por Balthasar Caymox $(+1635)$, en que se representan caligramáticamente los instrumentos de la Pasión: la columna, un látigo, la corona, la lanza, la cruz, los dados, etc. Una pirámide en prosa latina, dedicada al Elector Georg-Wilhelm de Brandemburgo, aparece en Pyramis literaria aeterna Divi Georgii Wilhelmi Morchiens Brandenburgiensis de Valentin Thilo. ${ }^{123}$ En el drama Der leidende Christus, in einem Trauerespiele vorgestellt de Johann Klaj (Klajus) ${ }^{124}$ aparece otro technopaegnion con forma de cruz, debido a Rudolf Karl Geller. Michael Franck compuso para el Viernes Santo de 1646 un poema más en forma de cruz, que editó en Coburg J. Eyrich y está en la biblioteca de Wolfenbüttel. Un cáliz en alemán puede verse en el folleto anónimo Hochzeit-gedicht Herrn Michael Beringen ${ }^{125}$ (f. A2v). Otro cáliz en latín, de Petrus Langiades, figura en Amores Tesemeria-Rhetiani

\footnotetext{
${ }^{122}$ Typis G. Corvinij, Worms, 1630, 7 vols.

${ }^{123}$ Praelae Reusnerianae, Königsberg, 1642.

${ }^{124}$ Wolfgang Endter, Nürnberg, 1645.

${ }^{125}$ Jacob Jeer, Griefswald, 1647.
} 
(1650). Una columna anónima en latín, impresa por De Villiers, homenajeó en Bremen, el 20 de junio de 1652, al clérigo Caspar Schacht. "El Cuerno de la Abundancia" se titula otro caligrama de Johann Steinmann, editado en 1653. En el Anni hujus novi MDCLV Auspicium de Johannes Johan Beck o Becker (1655) aparece, según Higgins (p. 40-41) "a curious circular poem suggesting the solar system". Un folleto anónimo de 1657, Condolentia et affectus statua [...] Johanni Dillies, ${ }^{126}$ contiene una cruz de Friedrich Schermer (f. C2r) y un monumento de Caspar Voigt (f. B2r). Del propio Schermer es un caligrama en alemán, con forma de monumento, editado en Adlicher Wittwen-Kranz. ${ }^{127}$ En el Janus Christianus de E. M. von Stain ${ }^{128}$ se incluye uno en forma de letra A. Christoph Völschen recogió una pirámide en su Tuba Augusteae, impreso de felicitación de cumpleaños publicado en 1663, y en el análogo Paschalia Seleniana, de 1664, una columna. Ambas hojas están en la Herzog August Bibliothek. De 1675 es un poema-pirámide publicado en el folleto de J. C. D., Als die weyland [...] Anna Maria [...] Thomae ${ }^{129}$ (f. 2v). En el volumen IV del libro Vivat Unordnung de Matthias Abele $(+1677)^{130}$ figura (p. 465) un caligrama en forma de palmera, y otro análogo en el volumen V de la misma obra (p. 105). En 1685 el impresor Lorentz Klönbohm editó en Göteborg dos pirámides más en alemán, compuestas por J. J. Fabricius en honor de Georg Friedrich y Ludwig von Aschenberg. Higgins (p. 74) sostiene que este Fabricius es el mismo que ha aparecido arriba como destinatario de un caligrama fúnebre, pero, ya que el poeta-profesor J. Fabricius murió, como se ha podido ver, en 1671, resulta algo problemático admitir que es el mismo Fabricius autor de estas dos pirámides de 1685. El año siguiente aparece un reloj de arena en Die Leiche des weyland collen [...] Hn. Caspar Sachsens de Gottfried Küpffender ${ }^{131}$ (f. 2v). Michael Hörnlein compuso, también según Higgins (p. 77), un poema-fuente. Martin Gosky (ca.1586-1656) es autor de un caligrama latino en forma de copa que figura en su Arbustum vel

\footnotetext{
$\overline{{ }^{126} \mathrm{M}}$. Höpfner, Alten Stettin, 1657.

${ }^{127}$ Georg Goetzken, Alten Stettin, 1658.

${ }^{128}$ S. e., Wolfenbüttel, 1659.

${ }^{129}$ Gottfried Gründr, Breslau, 1675.

${ }^{130}$ Endter, Nürnberg, 1670-1675, 5 vols.

${ }^{131}$ Baumann, gedruckts Johann Günther Roerer, Breslau, 1686.
} 
arboretum augusteum, aeternitati ac domui Augustae selenianae sacrum [...], ${ }^{132}$ y de otra copa dedicada a la Duquesa de Braunschweig-Lüneburg, Sophie Elisabeth, el día de su cumpleaños, el 20 de agosto de 1648, editada en un impreso que se conserva en la Herzog August Bibliothek de Wolfenbüttel. En 1696 aparece el folleto de David Mayer Der mensch ein lebendiges Kreuz [...] Herrn Andreae Watsgottes, ${ }^{133}$ que recoge un texto en forma de cruz. En el libro de homenaje Phoebus genethliacus serenissimo principi ac domino Christiano Augusto comite Palatino, Rheni,

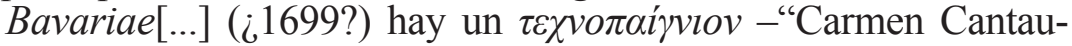
rinum"- en forma de sol. De Hermannus Kircher es otro poemapirámide en latín dedicado Enrique IV de Navarra. El impresor Johann Kankel (1614-1687), alemán de origen pero residente en Suecia, es autor de seis technopaegnia con forma de laberinto, forma a la que en varios casos se superpone otra: un corazón, una lápida, una pirámide, etc. ${ }^{134}$

En las Gratulationes in reditum [...] Sigismundi III del polaco Valerius Montelupi de Mari, ${ }^{135}$ donde se celebra la victoria de aquel rey sobre los moscovitas, aparecen cinco caligramas en latín: una puerta y un arco del triunfo (f. D2v), dos pirámides (f. D3v y D4r) y una pirámide invertida (f. D4v). Otras seis pirámides en latín figuran en el libro colectivo Logion episcopale illustrissimi [...] Domini Simonis Rudnicki [...] Episcopi Varwiens a studiosa iuventute Collegij Brunsgergeia. Soc. Iesu [...] evoltum, ${ }^{136}$ que se dedicó al obispo de Warmia, Szymon Rudnicki. Sus autores, alumnos de los jesuítas, son Ioannes Smogulecki (f. D3r), Samuel Piasecki (f. E3r), Martinus Badach (f. F3r), Andreas Kowalski (f. C2r), Albertus Hosius (f. H3r) y Henricus a Creuz (f. C3r). Otra pirámide más en latín aparece en Insula Geronomia [...] D. Stanislaus Kiszka de Stefan Mlodinski ${ }^{137}$ (f. 4v). Una más, en homenaje al Papa Paulo V, puede verse en Monumentum ad maiorem D. $O$. M. gloriam de Jeremiasz Dembinski. ${ }^{138}$ De la misma fecha es un

\footnotetext{
${ }^{132}$ Ex officina ducali Wolpherbyttani, Typis Johan et Henr. Stern, Wolfenbütel, 1650.

${ }^{133}$ Baumann, druckts Johann Günther Rörer, Breslau, 1696.

${ }^{134}$ Cf. Dick Higgins, Pattern Poetry..., p. 92.

${ }^{135}$ Wolrab, Poznan, 1611.

${ }^{136}$ Typis Schöfelsianis, Brunsbergae, 1612.

${ }^{137}$ Jozef Karcan, Vilnae, 1614.

138 S. e., Kraków, 1617.
} 
carmen figuratum en polaco que dibuja el escudo de armas de la familia Chalecki en la obra de Stanislaw Serafin Jagodynski Nymphica mosciwego pana I. M. P. Alexandra Chaleckiegona Chalczu [...] Iey Moscia P. P. Anna Magdalena Woynianka. ${ }^{139}$ Los alumnos de colegio jesuítico de Kalisz hicieron caligramas en latín que se recogieron en un libro dedicado a Henryk Firley, "Leopardus", titulado Illustrissimi ac reverendissimi Dno. Henrici Firley ${ }^{140}$, al ser éste consagrado obispo. Cada poema del libro tiene alrededor un recuadro y el nombre de Firley inscrito dentro de su texto. Ahí aparecen un poema-escudo de Martinus Gloszowski (f. F2v), una pirámide de Alexander Jawornicki (f. A $1 \mathrm{v}$ ), la fachada de una catedral de Albertus Kobierzycki (f. G2r), un anillo de Christophorus Poniatowski (f. M1r), una mitra de Andreas Radolinski (f. G3r), una columna de Sventoslaus Rudnicki (f. D2r), una pirámide de Nicolaus Sokolowski (f. C2v), un faro de Ioannes Suchorzowski (f. L1v), un edificio de Ioannes Szudelski (f. N2r) y una cruz de Andreas Zawissa Trzebicki (f. K2r). Otra pirámide, pero en griego, se editó (p. 7) en el Eparkhias de Adam Draski $(+1648) .{ }^{141}$ En latín está otra que se imprime (f. D3r) en un libro colectivo compuesto por estudiantes del colegio jesuítico de Kiev en honor de su obispo: Mnemosyne slawy, pracy trudów [...] Piotra Mohily, wojewodzica ziem moldawskich [...] od studentów gymnasium w bractwie Kijo-

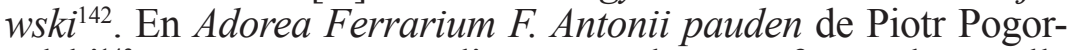
zelski ${ }^{143}$ se encuentra un caligrama en latín en forma de estrella (f. Clv). Cada una de sus puntas es una $A$ en posición horizontal, que en todos los casos termina y comienza palabra. Florian Lepiecki recogió cuatro pirámides en su Lampas extincti loci sideris aeternum [...] in funere [...] Caeciliae Renatae [...]Reginae. ${ }^{144}$ Wojciech Wasniowski publicó en su Wielkiego boga wielkiej matki ogródek $^{145}$ un caligrama en forma de estrella (f. K1v) y otro en forma de cruz (f. K2v), ambos en polaco. Ludwik Ferdynand Przeczkowski recoge un monumento en latín (f. A4r) en Sarmatici

\footnotetext{
$\overline{139}$ Józef Korczan, Wilno, 1617.

${ }^{140}$ Albertus Gedelius, 1624.

${ }^{141}$ Typis Francisci Cesarij, Kraków, 1631.

${ }^{142}$ S. Cudolworna Lawra. Piecz. , Kiew, 1633.

${ }^{143}$ Acad. Zamoscen, Zamosc, 1639.

${ }^{144}$ Valerianus Piatkowski, Kraków, 1644.

${ }^{145}$ Francisek Cezary, Kraków, 1644.
} 
labores Herculi mortalitique inmortalitatio, imperennaturo sculpti colosso. ${ }^{146}$ En Bos loquens de Pominio Gisberto ${ }^{147}$ hay otro caligrama en forma de columna. En la biblioteca Czartoryski se encuentra un tratado de Retórica manuscrito, fechado en 1659, obra de un grupo de alumnos del colegio de los jesuítas de Kroze, en la Lituania polaca. En él figuran, además de otros poemas visuales ajenos al caligrama, una rueda de la fortuna (p. 679), un laberinto con forma de diamante (p. 688), un fragmento de poema-sol (p. 689) y una pirámide con acróstico (p. 689). El folleto Triumphans Herculae victus ${ }^{148}$ de Rafal Kazimierz Artenski contiene (f. K2r) una pirámide en latín. Otra pirámide, una bandera y una espada con acróstico figuran en las p. 58, 51 y 60, respectivamente, del libro de Ignacy Krzykiewickz Attica musa thitoream et hyampeum, ${ }^{149}$ que en sus p. 46-55 se ocupa de la poesía figurada y aliterativa. Jakob Teodor Trembecki incluye otro caligrama en polaco, éste en forma de rueda, en su tratado Wirydarz poeticki viridiarum (1675). ${ }^{150}$ En la Biblioteka Academiei Romana de Bucarest hay un manuscrito polaco anónimo e incompleto, en latín, titulado Miscellanea de poetica, fechado en 1685. En él aparecen un poema-cruz y otro que representa el blasón del obispo Barlaass Jedlinski. El Technopaegnion sacropoeticum venerabili corporis Christi festo, pietatis ergo consecratum de Iano Tyrigeta Germano ${ }^{151}$ contiene, entre otros artificios visuales, una serie de tres poemas-cruz, "Rabanianae artificiosae figurae" (f. B2r).

Higgins (p. 138-143) da cuenta de una serie de technopaegnia localizados en Gdansk por Piotr Rypson, en su mayoría en lengua alemana, publicados en folletos u hojas sueltas impresos en Polonia, en los distintos talleres de la familia Rhete, aunque en su mayor parte no son propiamente caligramas, sino "laberintos cúbicos" o composiciones con versi intexti. Hay entre ellos, sin embargo, un poema-copa nupcial anónimo en alemán, impreso en

\footnotetext{
$\overline{146}$ S. e., Paris, 1644.

${ }^{147}$ Io. Baptista Pasquati, Padova, 1664.

${ }^{148}$ Stanislaw Piotrkowczyk, Kraków, 1672.

${ }^{149}$ Apud Albertum Gorecki, Kraków, 1674.

${ }^{150}$ Ed. de Aleksander Brückner, Towarzystwo dla Popierania Nauki Polskiej, Lwow, 1910-1911, 2 vols.

${ }^{151}$ In officina Lazari, Kraków, 1698.
} 
Gdansk con ocasión de la boda de Johannes Ernst Schmieden; ${ }^{152}$ un caligrama en latín, de Andreas Coien, impreso en 1607 para el casamiento de Michael Wieder, que dibuja dos árboles con sus ramas entrelazadas, ${ }^{153}$ otras tres copas nupciales de Petrus Witzke -dos de 1611, en alemán, escritas para la boda de Tobias Gasten, ${ }^{154} \mathrm{y}$ la otra, en el mismo idioma, hecha para en enlace del notario Franz Adrian en 1621-, ${ }^{.155}$ del propio Witzke son otro poema nupcial en alemán, que representa una campana (con un mesóstico y una cruz "intexta"), creado para Andreas Ulrich y Christina Spiessen, que se casaron el 24 de agosto de $1621,{ }^{156}$ y un par de copas - una en alemán y otra en latín- que en 1612 conmemoraron en una hoja sin título el matrimonio de Joann. Philippus Pierius; otro caligrama en alemán, en forma de corona con un laberinto, fue compuesto en 1640 por Bartholomaeus Rothmann en honor de Johann Rossow; ${ }^{157}$ del mismo autor, y posiblemente de igual fecha, es otra corona que conmemora la boda de Herr Schmalenberg; otra copa de bodas en alemán, de 1644, fue hecha por Solomon Wahl para el enlace de su hermano Johannes; ${ }^{158}$ otra copa, asimismo en alemán, se publicó, según Dick Higgins (p. 144), en un folleto impreso en 1644 para la boda de Daniel Schaeucken y Anna Rosenberg; tres corazones en latín y otros tres en alemán se deben a Jakob Zetzke (Jacobus Zetzkius) (+1671), que los compuso para las bodas del cónsul Niklaus von Bodeck y Konstanz Giesen, el 30 de junio de 1648; ${ }^{159}$ para esta misma ocasión Christianus Ziegerus, Michael

\footnotetext{
${ }^{152}$ Ad generosum dominum sponsum [...] Herr Johannes Ernst Schmieden Brautigam.

${ }^{153}$ Viridarium in honorem et festivitate nuptiarum [...] Dni. Michaelis [...] Dni. Georgii Wiederi in Rep. Elbigensis Consulis [...] fili sponsi.

${ }^{154}$ Epithalamia in solemnem nuptiarum festivitatem [...] D. Tobiae Gasten Pomerani.

${ }^{155}$ Freuden-Becher zum Hochzeitlischen Ehren des [...] Hn. Francisci Adriani, Notarii Publici, Brautigams.

${ }^{156}$ Freuden-Glöckein zum Hochzeitlichen Ehren des Erbarn [...] Andreae Ulrici, Signatoris zur Farr/Brautigams, wo wol der ehren Tugentsamen Jungfrawen Christinae des Erbarn und Kunstreichen Christoph Spiessen vielgeliebten Mödder Braut.

${ }^{157}$ Ein zierlicher Ehren Kranz mit manscherlei schönen Kreutzer- und Blumen werck des Glücks auff Labyrinthische Arth besetz, gewunden und gebunden.

${ }^{158}$ Impreso en Festivitate nuptiale, fratri suavissimo Johanni Wahlio sponso lectissinaque virgini Elesabethae Friderici sponsae, 21 de enero de 1644.

${ }^{159}$ Eydilla nuptiis secundis [...] Nicolai a Bodeck [...] Reip. Gedans. consulis [...] nobilisimaeque virginis Constantiae [...] Salomonis Gisii filiae exhibita.
} 
Albinus, Johann Peter Titz (Titius), Bartholomaeus Manhart y acaso algún otro colaborador hicieron una copa en latín; ${ }^{160}$ un ataúd de Daniel Schrader fue escrito en alemán para el funeral de Gregor Düstenwaldts en 1657; ${ }^{161}$ Johann Caspar Zetsching publicó en 1666 un caligrama en forma de sol, con el título en latín pero el texto en alemán, para celebrar la ordenación sacerdotal de Eilard Fridrichsen, ${ }^{162}$ y el mismo año otro similar, éste íntegramente en alemán, en honor de Georg Schroeder; ${ }^{163}$ de 1682 es un texto latino anónimo que dibuja el escudo de Jan III Sobieski. ${ }^{164}$

De los caligramas escandinavos no había tenido noticia alguna hasta que en el libro de Higgins encontré referencias a los, ya aludidos, de Iacobus Nicholai de Dacia y (p. 89-93) a otros de fechas más recientes, ya en lengua vulgar. El poeta y tratadista de Retórica Peder Jensen Roskilde compuso en 1627 un poema-copa nupcial en danés, dedicado al Real Canciller Christian Friis y su esposa, Barbara Bittrop. Al pastor Nicolaus Petersen, de Elmeshorn, se debe un "inusual" (para Dick Higgins, p. 89-90) ejemplar en alemán, incluido en la cubierta de un folleto de homenaje al Profesor Johannes Birkenbusch cuyo título es Dankschüldige Ehrengedächtniss dem Johannes Birkenbusch. ${ }^{165}$ En él las palabras del texto -"Die Schamt / Der Welt/ ihr eis/ telfeit!"-se disponen sobre el papel según la distribución de los cuatro puntos cardinales o los extremos de una cruz, pero al no haber relación entre esta presentación gráfica y el significado no podemos hablar de un caligrama en sentido estricto. En Suecia la práctica del caligrama parece haber tenido más aceptación que en Dinamarca: Higgins recoge (p. 90) el testimonio de Ulf Gran, de la Universidad de Lund, según el cual se conocen en torno a 120 muestras del siglo XVII, tanto en sueco

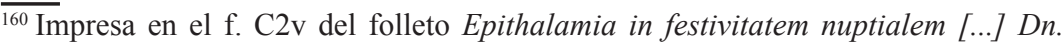
Nicolai von Bodeck [...] nunc secundo sponsim et virginis [...] Constantiae viri magnifici nobilissimi amplissimique Dn. Salomonis Giesen.

${ }^{161}$ Bei sehligem Ablaiben des [...] Herrn Gregor Düstenwaldts ansehnlichen Bürgers.

${ }^{162}$ Sphaero-Lycophronticum quod antiqua generis prosapia, doctrina, rerum eximiarum scientia atq. experientia nobilissimo Domino Eilard Friderihcsen [sic].

${ }^{163}$ Sphaero-Lycophronticum quod antiqua generis prosapia, doctrina, rerum eximiarum scientia atq. experientia nobilissimo Domino Georgio Schroeder.

${ }^{164}$ En un folleto anónimo titulado In serenissimi [...] Johannis Tertii Dei gratia regis Poloniae [...] nominis regii anagramma carmen, David Fredericus Rhetius, Gdansk, 1682.

${ }^{165}$ Melchior Kochen, Glückstadt, 1679.
} 
como en latín o griego. Predominan los escritos para conmemorar bodas. Una campana de autor anónimo, editada en 1693 por el impresor real, Niclas Wankjiff, celebró la de Jacob Aschengreen y Elisabeth Bure. Para la de Carl Feiff y Elisabeth Rampe en 1677 y la de Davidh Kampe y Margareta Magdalena Ebertz en 1691 se imprimieron, pudiera decirse con no mucha delicadeza, sendos laberintos. Los esponsales de Andreas Phaleen, en 1697, se celebraron con un elegante caligrama en forma de violín, debido a Israel Phaleen. Alexandre Petre compuso para el funeral de Ericius A. Holsteen (1647) un texto anónimo en forma de corazón. En las paredes de la Biblioteca Real de Estocolmo dice Higgins haber visto colgados dos caligramas asimismo anónimos: una copa de 1652 y una original representación de la muerte con su guadaña, también de mediados del 600. A la década de 1670 hay que adscribir un reloj de arena que Christianus Biccius compuso en honor del rey Carlos XI de Suecia en su Carolus Undecimus Rex Swediae [...] in plausum auspiciatissimi nominalis [...] festi [...] Dni. Caroli XI regis Svecorum. ${ }^{166}$ En 1681 Johan Georg Ebert imprime en Estocolmo una pirámide en honor de Matthias Sygman. Un año más tarde publica Johan G. Gazelius, para la boda de B. Hagen, un caligrama con la forma del globo terráqueo. En un folleto dedicado por Daniel Treutzel a la memoria de Olof Sparrman en 1690 se incluyen, según Higgins (p. 93), caligramas en sueco en forma de rueca, reloj de arena, candela y monumento. Otro, anónimo, en latín y con forma de templo, se imprimió en Estocolmo en 1691 en honor de Maria Lemmens. En Finlandia encontró Higgins ( $p$. 93) algunos caligramas barrocos, aunque ninguno de ellos escrito en finés. ${ }^{167}$ Cita dos cálices en latín, ambos sin fecha, pero probablemente de finales del XVII. Uno se debe a Andrea Thuroneus Kyroensi/Finnone; el otro es anónimo, y quizá del mismo autor, por las semejanzas que guarda con el anterior.

En el libro del holandés Herman Hugo Pia desideria ${ }^{168}$ se incluye, según Higgins (p. 95), un texto con forma de cruz. En 1626 aparece en Amberes una obra del dominico I. de Weerdt titulada

\footnotetext{
${ }^{166}$ Typis Danielis Storckii, Alten Stettin, s. a.

${ }^{167}$ Afirma, sin embargo (p. 93), que el estudioso J. O. Mallander, de Helsinki, le comunicó en 1982 que sí existían caligramas finlandeses en lengua vulgar.

${ }^{168}$ Henricus Aerisseus, Antwerpiae, 1624.
} 
Parnassi bicipitis de pace vaticinia, chronographicis, retrogradis, acrostichis et anagrammatis explicata ${ }^{169}$ de la que Pozzi (p. 130) dice que contiene dos estrellas, una de ellas con cola (p. 96 y 97), pirámides y columnas (p. 100-101).

En Inglaterra, en 1602 se publica por primera vez la antología A poetical rhapsody, reeditada en $1621,{ }^{170}$ donde hay un poema, que Higgins atribuye (p. 98) a Francis Davison, en forma de altar. En un homenaje fúnebre a la reina Isabel que imprimió la Universidad de Oxford en 1603, In memoriam honoratissimam [...] Elisabethae reginae, ${ }^{171}$ figuran (p. 61) un par de alas de Robert Pinck (1573-1647), un altar (p. 98) de Thomas Winniffe (1576-1654) y un monumento (p. 105) de John Chichester, todo en latín. Josuah Sylvester (1563-1618) dispuso en forma piramidal una dedicatoria a Sir Philip Sydney en su traducción de Du Bartas: Bartas: his deuine weekes and works (1605). ${ }^{172}$ William Browne (1590-ca. 1645), al que me limité a nombrar en mi libro (p. 41), incluyó otro altar en The Shepheard's pipe ${ }^{173}$ (f. E1v), y en Britanias's Pastorales $^{174}$ una serie de flautas (p. 60). Un globo, único en la tradición inglesa, se encuentra, según Higgins (p. 99-100), en el folleto The Ten Commandments de Richard Jackman (1620). George Wither (1588-1667) incluyó en su Fair virtue (1622) una serie de seis sonetos con forma de rombo. ${ }^{175}$ En The celestiall publican de Nathanael (o Nathaniel) Richards (ca. 1600-?) $)^{176}$ pueden verse un diamante también en forma de rombo (f. 15r), dos cruces (f. C8r y f. C8v) y el árbol del Paraíso (f. D1r). Francis Quarles (1592-1644), al que en mi libro (p. 41) sólo mencioné como autor de caligramas, imprimió en Divine fancies (1632) un rombo y en Hieroglyphikes (1638) un altar o reloj de arena, una serie de ocho

\footnotetext{
$\overline{{ }^{169} \text { Ex }}$ officina Plantiniana, Antwerpiae, 1626.

${ }^{170}$ Cf. A poetical rhapsody (1602-1621), ed. de Hyder E. Rollins, Harvard University Press, Cambridge, MASS., 1931.

${ }^{171}$ Barnes, Oxford, 1603.

${ }^{172}$ Ed. facsímil en Scholars Facsimiles and Reprints, Gainesville, FL, 1965, y también Joshua Sylvester, The divine weeks and works of Guillaume de Saluste, Sieur de Bartas, ed. de Susan Synder, Clarendon Press, Oxford, 1979, 2 vols.

${ }^{173}$ Printed by N. O. Kos for G. Norton, London, 1614.

${ }^{174}$ George Norton, London, 1616.

${ }^{175}$ Cf. The Poetry of George Wither, ed. de Frank Sidgwick, AMS Press, New York, 1968, 2 vols.

${ }^{176}$ Imprinted by Felix Kyngston for Roger Mihell, London, 1630.
} 
pirámides, otra de cinco rombos y otra de veinticuatro pirámides más. ${ }^{177}$ Thomas Stanley (o Stanly) (1625-1678) compuso una serie de tres pirámides, recogidas en el f. 161r de un manuscrito de $c a$. 1645 de la Universidad de Cambridge. Robert Baron (1593-1639) publicó en su 'Erotopathia, or the Cyprian academy ${ }^{178}$ un epitafio también en forma de ara (p. 30) y dos poemas de métrica creciente y decreciente respectivamente (p. 44), en los que es posible ver tanto sendas siringas como un par de alas. Aquel mismo año 1647 sale el libro de Christopher Harvey (1597-1663) Schola cordis, or The heart of itself gone away from God $^{179}$ en el que se encuentran diecisiete hachas (p. 22 y 74), trece rombos (p. 77 y 80), seis pirámides (p. 116) y seis pares de alas (p. 119). William Bosworth (1607-¿1650?) recoge en The chaste and lost lovers ${ }^{180}$ un caligrama más con forma de altar (p. 39), un corazón (p. 62) y otro par de alas (p. 63). En Theophila, or love's sacrifice de Edward Benlowes (1603-1676) ${ }^{181}$ aparecen dos altares caligramáticos -uno en inglés (p. 14) y otro en latín (p. 161)-, "Las cruces del Calvario", con acróstico, mesóstico y teléstico a la vez ( $\mathrm{p}$. 268) y una "Passio Christi" que imita la de Samuel Pomario. Tres poemas-rombo figuran en Occasions of spring, or poems upon several occasions de Matthew Stevenson (ca. 1620-1685). ${ }^{182}$ Dick Higgins alude también (p. 100) a la conocida antología Facetiae. Musarum deliciae; or the muses' recreation, recopilada por Sir John Mennes (1599-1621) y James Smith, quizá con algún otro colaborador $^{183}$-se ha mencionado alguna vez a George Herbert-, que conoció varias reediciones. En ella figuran, aparte varios jeroglíficos y lover's knot o "lazos de enamorado", ${ }^{184}$ dos textos en

$\overline{{ }^{177} \mathrm{Cf}}$. Francis Quarles, The complete works in prose and verse, ed. de Alexander B. Grossart, Edinburgh University Press, 1880, 3 vols.

${ }^{178}$ Printed by W. W. and are to sold by J. Hardesty, T. Huntington and T. Jackson at their shops in Ducklane, London, 1647.

${ }^{179} \mathrm{H}$. Blunden, London, 1647.

${ }^{180}$ Blaiklock, London, 1651.

${ }^{181}$ Henry Seile and Humphrey Mosely, London, 1652.

${ }^{182}$ N. Elkins, London, 1654.

${ }^{183}$ John Camden Hotten, London, 1658, 2 vols.

${ }^{184}$ Se trata de dibujos que representan cintas con entrelazados complicados, en las cuales van inscritos textos amorosos cuya lectura constituye una especie de rompecabezas. Son muy habituales en la Inglaterra del XVII, donde se usaban frecuentemente en las valentines. 
forma de altar y una columna fúnebre, en prosa burlesca, dirigida contra la volubilidad política de Andrew Turncoat. Samuel Speed (1631-1682) publicó tres caligramas en su Prison pitie, or meditations divine and moral: ${ }^{185}$ una cruz (p. 65), un altar (p. 72) y "The Bible", la Biblia (p. 81), caso único en la tradición inglesa. Un poema en forma de rombo titulado "The four seasons" (p. 409) y otro, "The Trophy", que dibuja una vez más un altar, figuran entre los Lyric poems, made in imitation of the Italians de Philip Ayres. ${ }^{186}$ El poeta y clérigo anglicano Joseph Beaumont (16161699) compuso dos textos en forma de huevo y otro en forma de columna salomónica, cuyos manuscritos se encuentran en la biblioteca del Wellesley College en Wellesley, Massachusetts, y se editaron en 1914 dentro de sus Minor poems ${ }^{187}$ (p. 153, 154 y 301-302). En 1658, Hugh Crompton recoge en Pierides, or the muses mount ${ }^{188}$ dos technopaegnia piramidales (C4r y G4r-4v). En Escocia, William Drummond de Hawthornden (1587-1649) incluyó en la última página de sus Poems $(1616)^{189}$ una pirámide rematada por una corona dibujada.

Ulrich Ernst menciona ${ }^{190}$ un caligrama en latín, en forma de pirámide invertida, que conmemoró en 1615 el asesinato del rey Enrique IV de Francia, y Higgins (p. 51) tres "modest crosses" en latín publicadas en el Apollonis spiritualis oraculum de Jacques Pochet. ${ }^{191}$

Dick Higgins cita también (p. 58) algunos caligramas barrocos húngaros: de Andreas Graff son un espejo, un huevo, un corazón, una pirámide, un hacha y un cono recogidos en su Metodica poetices praecepta in usum Scholae Solnensis. ${ }^{192}$ Según el propio Higgins (p. 61-62), Philipus Ludovicus Piscator se ocupa de los technopaegnia en su Artis poetices praecepta methodice concennata et perspicuis exemplis illustrata, ${ }^{193}$ donde, evidenciando su conocimiento de la tradición del caligrama, sostiene que sus

\footnotetext{
$\overline{185}$ Printed by J. C. for S. S., London, 1677.

${ }^{186}$ J. Knight and F. Saunders, London, 1687.

${ }^{187}$ Cf. The minor poems of Joseph Beaumont, D. D., 1616-99, ed. de Eloise Robinson, Houghton Mifflin, Boston, 1914.

${ }^{188}$ Printed by J. F. for Charles Webb, 1658.

${ }^{189} \mathrm{Cf}$. The poetical works of William Drummond of Hawthornden, ed. L. E. Kestner, Manchester University Press, 1913.

190 "Europäische...", p. 312.

${ }^{191}$ Johannis Mommorti, Bruxelles, 1651.

${ }^{192}$ Officina Typographica Dorotheae Wocalianae, Solna, 1642.

${ }^{193}$ S. e., Gyulafehórvar, 1642.
} 
formas más usuales son las de triángulos y cuadrados, rombos, trapezoides, círculos, cruces, cilindros, conos, pirámides, huevos, soles, corazones, torres, tumbas, órganos, altares, anclas, copas, púlpitos, ruedas, hachas, escudos, husos, ruedas, trípodes, copas, etc.

Aunque en Rusia el cultivo de la poesía figurada no tiene la importancia que en otros ámbitos lingüísticos, Higgins menciona (p. 146) unos pocos caligramas de los siglos XVII a XIX. Durante el XVII, Simeon Sitianovich Polotski (1629-1680) compuso, amén de otros $\tau \varepsilon \chi v o \pi \alpha i ́ v v l \alpha$ ajenos al caligrama, un poema-cruz, un corazón y una estrella ${ }^{194}$ El monje ucraniano Elysei Pletenechki es autor de un doble technopaegnion, impreso en una hoja suelta de 1623, que representa una luna en cuarto creciente y una cruz, ambos con elementos no-textuales. Lo recoge Higgins (p. 151).

\section{El siglo XVIII}

Entre los tratadistas de poética alemanes del siglo XVIII que prestan atención al caligrama, a los nombres de Redtel, Hunold, Omeis, Grüvel, Statius, Uhse y Gottsched (mencionados en la p. 42 de mi libro) agregaré ahora el de Johann Männling (16581723). Éste último, en Der Europaeische Helicon, Oder MusenBerg Das ist Kurtze und deutliche Anweisung Zu der Deutschen Dicht-Kunst Da ein Liebhabendes Gemüthe solcher Wissenschaft an [...] geführet wird Innerhalb wenigen Wochen Ein zierliches deutsches Gedichte zu machen, ${ }^{195}$ dice que los caligramas más corrientes son corazones, huevos, cruces, copas, floreros, cestas, espejos, estrellas, rosas, tulipanes, narcisos, árboles, pirámides, manzanas y féretros (p. 133), alude a los del Poetischer-Trichter de Harsdörffer y a los de Kornfeld (p. 133) y presenta cinco de su propia cosecha: una palmera -dedicada a D. Mayer en 1685- ( $p$. 134), un huevo (p. 134), un corazón (p. 135), una pirámide (p. 135) y un féretro (p. 136). El corazón y la palmera estaban ya en el Europäische Parnassus del propio Männling. ${ }^{196}$

\footnotetext{
${ }^{194}$ Izbrannie sochineniia, ed. de I. P. Eremin, Izdatel'stvo Akademij Nauk SSSR, Moskva, 1953, p. 113, 119 y 128, respectivamente.

${ }^{195}$ G. Dahlen, Alten Stettin, 1704.

${ }^{196}$ Brünings, Wittenberg, 1685.
} 
Además, Adler menciona y reproduce ${ }^{197}$ dos hermosos y originales caligramas que Gottfried Kleiner (1691-1767) hizo imprimir en su Garten-Lust im Winter: ${ }^{198}$ uno, con algunos elementos dibujados, tiene la forma de una iglesia; el otro traza la silueta de un cedro, basándose en el versículo 16 del Salmo CIV, que hace referencia al cedro del Líbano. Y Pozzi recoge (p. 140 y141) dos en forma de laberinto -no dos laberintos poéticos-: el primero, un impreso de 1748, cuyo autor es J. Roch von Hegnau, que se guarda en la Zentralbibliothek de Zürich y se titula Geistlicher IrrGarten, mit vier Gnaden Brunnen, da durch kürzlich angezeiget die vier Ströhme des Paradies und des glückseligsten Zustands vor dem Sünden-Fall [...]; el otro, en latín y alemán, está en la misma biblioteca y es anónimo y de 1758.

Dick Higgins da noticia (p. 84-88) de un buen número de caligramas dieciochescos alemanes, aunque señala que, pasados los primeros años de la centuria, esta modalidad literaria desaparece en gran medida, tanto en Alemania como en el resto de Europa. Él menciona dos muestras, anónimas y de fecha ignorada, con forma de laberinto, una conservada en la Zentralbibliothek de Zürich y la otra -ésta impresa en Darmstadt por J. Schirmer- en la Colección Mori del Museo Gutenberg de Mainz. En la p. 107 de Lehrmässige Anweisung zu der teutschen Vers-und Ticht Kunst de Johann Hofmann (ca. 1640-1703) ${ }^{199}$ aparece un poema-copa. Otra copa (f. H8v), y además una cruz (f. H7v), un cesto (f. H8v), una sopera (f. I1r), un huevo (f. I1v) y un corazón (f. I2v) pueden verse en el libro de Friderich Redtel Ein nothwendiger Unterricht von der teutschen Versekunst ${ }^{200}$. Un memorial fúnebre en honor de Rodolfo Augusto de Braunschweig, cuyo texto configura una pirámide, fue compuesto por Christian Ludwig Ermisch e impreso en 1704. De 1707 son dos pirámides y una cruz publicadas por Christian Fiedrich Hunold, "Menantes" (1680-1721), en Die allerneueste Art, zur reinen und galanten poesie zu gelangen. ${ }^{201} \mathrm{El}$ algo posterior Die alterneueste Art, zur Reim und galanten Poesie de Erdmann

\footnotetext{
197 “Technopaigneia, carmina figurata...”, p. 120-121 у p. 133 у 135.

${ }^{198}$ Diet. Krahnen, Hirschberg, 1732, p. 95 y 93, respectivamente.

${ }^{199}$ Johann Zieglr, Nürnberg, 1702.

${ }^{200}$ C. Schröder, Stettin, 1704.

${ }^{201}$ Johann Wolfgang Fickweiler, Hamburg, 1707.
} 
Neumeister (1671-1756) ${ }^{202}$ contiene otras dos pirámides (p. 266, 267) y otra cruz (p. 268). En un $m s$. de 1713 que se conserva en el Archivo Estatal de Elbing -copia hecha por el clérigo Wilhelm Rupson de otro fechable en 1636-, en cuya portada ya el texto se dispone en forma de pera, figura un cáliz (p. 3). Higgins cita un caligrama anónimo, una pirámide, impreso por Hermann Brauer para el funeral de Wommelia Schönne en 1715, del que hay un ejemplar en la biblioteca universitaria de Bremen. Heinrich Trier ofrece a Maria Sybilla von Rantzau, en el Año Nuevo 1718, uno en forma de rosa, editado en Wolfenbüttel por Christian Bartsch, que se encuentra en la Herzog August Bibliothek. Otro carmen figuratum anónimo, de impresor, lugar y fecha igualmente desconocidos, que dibuja la portada de una iglesia, fue creado hacia 1720 para la boda de Christian Bartsch y Sophia Leiding. Se encuentra en la Herzog August Bibliothek. En 1721, con ocasión del enlace de Johann Meybohm y Mette Oriana Hollen, Hermann Christoph Jan imprimió un poema-árbol anónimo en una hoja de la que hay un ejemplar en la Bremen Bibliothek. De ese mismo año es un jarrón anónimo, editado para el matrimonio de Nicholas von Offenbach, Canciller de la ciudad de Frankfurt. Otro caligrama en forma de sol fue impreso por Erben Cattepoels en 1722 para el matrimonio de Johann Jakob Schluiter y Anna Magdalena Biben, y se guarda en la biblioteca de la Universidad de Bremen. De 1723 es un laberinto cuadrado compuesto por Ernst Friedrich Kielburg en homenaje al Rector de la Universidad de Altdorfer, Johan Jakob Baier. Higgins añade a los dos citados por Adler algunos otros caligramas del Garten-Lust im Winter de Gottfried Kleiner: una parra (p. 92), un castillo (p. 94), dos pirámides (p. 96 y 97) y un ataúd (p. 98). Una copa figura en Deutliche und grundliche Einleitung zu der reinen deutschen Poesie de Andreas Köhler. ${ }^{203}$ En 1742 aparece otro poema-copa, anónimo, estampado por Hermann Christopher Jan con ocasión de la boda de Dietrich Smidt y Amalie Schöner, conservado en la biblioteca citada de Bremen. En la Colección Mori del Museo Gutenberg de Mainz hay otro, de 1744, en forma de estrella, que felicita el Año Nuevo. En este mismo museo hay

\footnotetext{
${ }^{202}$ Johann Wolfgang Fickweiler, Hamburg, 1712.

${ }^{203}$ S. e. , Halle, 1734.
} 
un impreso con otro caligrama de Año Nuevo en forma de copa, editado en 1754, que menciona y reproduce Higgins (p. 84).

Lo mismo que en Alemania, en Dinamarca fue habitual componer carmina figurata para conmemorar las bodas: cuando en 1711 se casaron el Doctor Johann Fischer y Margaret Mälber se imprimió uno, anónimo, en forma de cáliz o copa; otro semejante (conservado en la colección de pliegos con poemas nupciales $-\mathrm{O}$ "Lejlighedsdigte" - de la Biblioteca Real de Kobenhavn) se hizo con ocasión del enlace de August Breseman y Anna Dor en 1719; de 1758 es otro dedicado a Nicolaus Mollerand y Catherine Wendelia Berling. El casamiento de Friedrich Adolph Hansen y Catherine Braten, en 1704, dio lugar a una hoja con un caligrama anónimo en alemán en forma de pirámide, conservado en la citada colección de la Biblioteca Real. Con otro poema-copa en danés, igualmente anónimo, se homenajeó al rey Christian VII en el periódico Adresse-Contoirs Efterretninger de Odense el 23 de febrero de 1776. En el folleto Danske Pyramider (1700) de Peder Cappel (1664-1727) aparecen dos columnas.

En Suecia, Johan Runius (1679-1713), uno de los principales poetas barrocos suecos, incluyó en una carta un poema en forma de copa de vino, que se imprimiría por primera vez en el número 2 de Samlade skrifter, 1934-1935, y en su libro Hercules hizo referencia a la tradición del carmen figuratum.

En Rusia, Gavriil Romanovich Derzhavrin (1743-1816) hizo un poema-pirámide, dado a conocer por Dimitri Tschizewski en 1958. ${ }^{204}$ El ucraniano Mytrofan Dovhalevski incluyó en su Hortus poeticus (1736) un corazón coronado y una cruz, ambos en latín. De esa obra existen dos manuscritos en la Biblioteca Central de Investigación de la Academia Ucraniana de Ciencias (Kiev). A su compatriota Ivan Velichkovski (1687-1726) se deben una hoguera y una pirámide, ambas recogidas en el libro Tvorij. ${ }^{205}$

El croata Ignjat Dordjic (1675-1737) es autor de un caligrama en forma de cruz de Lorena sobre un pedestal, que menciona y reproduce Higgins (p. 150-151).

El propio Higgins alude en su espléndido libro (p. 94) a dos caligramas en holandés, que representan una tetera y un jarrón,

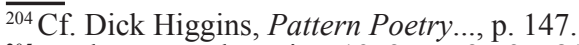

${ }^{205}$ Naukova Dumka, Kiev, 1972, p. 72-73 y 81-82, respectivamente. 
recogidos en el libro anónimo Die nieuwe nassauwse princelyke schenkhan (1708).

En la biblioteca del Trinity College de Dublín se conserva un manuscrito en el que hay un texto en gaélico, en prosa (p. 90), con forma de pirámide invertida, que sirve de introducción a un poema de Cathan O'Duinin.

Pozzi menciona (p. 120, 121, 130, 132 y 135-136) varios technopaegnia en latín, en forma de bandera (con acróstico en el asta), de copa, de corona, de sol, de estrella y de rosa, debidos al húngaro István (o Stephanus) Lepsényi, que se conservan en un manuscrito de ca. 1700 que, con el título Poesis ludens seu artificia poetica quadam ex variis authoribus collecta, caetera labore et sudore S. L. composita [...], se guarda en la Biblioteca Nacional de Hungría, en Budapest (folios 93v, 94r, 98r, 100r, 105 r y 105bis). La rosa es muy parecida a la publicada en Poesis artificiosa. A estos caligramas de Lepsényi, pero citando una bandera, una estrella, una rosa, un castillo, una Y, una corona, una rueda con radios, un sol, un laberinto y un corazón, alude asimismo István Kilián en su artículo citado de 1980, que menciona además otros carmina figurata de autores húngaros: poemas en forma de estrella, pirámide, rosa y una especie de acordeón de Lukács Moesch y un poema-tulipán en su jarrón de György Palocsai, y también varios elogios fúnebres de estudiantes del colegio Sárospatak ${ }^{206}$ en forma de cruz, y uno en forma de flor con sus raíces, ${ }^{207}$ obra del alumno Samuel Szentpéteri. ${ }^{208}$ Lo cierto es que estos textos son en su mayoría, a la vez que caligramas, laberintos y mesósticos o acrósticos: en la cubierta de ese número de la revista Új írás se reproduce un textosol, que tiene dibujada en el centro una cabeza antropomórfica rodeada de eses mayúsculas, y una línea ondulada en el medio de cada rayo. Leídas en el sentido de las agujas el reloj, las letras mayúsculas del extremo de cada uno de los rayos, formados por dos líneas de texto, conforman la frase "VIVATIOANNES". Por

\footnotetext{
$\overline{206}$ El volumen, según Dick Higgins, Pattern Poetry..., p. 58, se tituló Pataki diákok halotti búcsúztatói y se encuentra en la biblioteca de la Tiszántúli Református Egyházkerület Sárospataki Nagykönyvtára, nº 1124.

207 "A régi ...", p. 33.

${ }^{208}$ Lo menciona y reproduce Dick Higgins, Pattern Poetry..., p. 58-59.
} 
otra parte, la misma $S$ central en que termina una frase es el inicio de la siguiente. ${ }^{209}$ En las páginas que preceden al trabajo de Kilián aparecen un corazón con un acróstico central (p. 19), una rosa (p. 20), un hacha (p. 21), una cruz (p. 22), la rueda-cuyos radios convergen en una $O$ central- (p. 23), la estrella, con un artificio análogo al ya contemplado en el sol (p. 24), el castillo -a vista de pájaro- (p. 25), la bandera (p. 26), un conjunto de cuatro cruces (p. 27), la corona con laberinto y doble mesóstico (p. 28) y también el tulipán en el vaso (p. 29) de Palocsai, cuya descripción sería inevitablemente confusa.

Higgins da cuenta (p. 58-59) de otros caligramas húngaros del XVIII: un texto latino con un "IESUS" dispuesto en forma de cruz, con acróstico, mesóstico y teléstico, de György Lányi, recogido en el manuscrito Kz. 1018 de la Biblioteca Luterana de Késmárk (1708-1710); una copa manuscrita de 1711 incluída en el tomo I (p. 371) del Itinerarium Bucholtzianum de György Bucholtz (1688-1757), que se conserva en la biblioteca checa Matica Slovenska; un caligrama en forma de sol y otro poemacorazón (f. D1r), una rosa, una fuente y un león (f. D2r) y una cruz (f. D2v), todos en latín, aparecidos en Domus Austriacae curae sive tripudium genethalicum [...] Archiducis Austriae ${ }^{210} \mathrm{de}$ Imre Csaki de Kerestszegh; a Gergely Molnár se deben, también según Higgins (p. 61), carmina figurata en forma de pirámide, flor, cruz (con mesóstico), corazón y rueda, reunidos en Elementa gramaticae latinae. ${ }^{211}$

El polaco Idzi Stefan Wadowski (+ 1721) recoge, según dice Higgins (p. 138), un caligrama en prosa, con forma de diamante, en la última página de su Liber votivus. Su compatriota Maurycy Kielkowski publicó en su Hypomena Franciscanum ${ }^{212}$ un poema-estrella en latín (f. E1r), en cuyo centro hay una $S$ en que comienzan y terminan los versos, y un reloj de sol (f. E2r). Józef Walenty Tomaszkiewicz recoge en Arbor laureato ${ }^{213}$

\footnotetext{
${ }^{209}$ Aclararé que si una línea debe leerse de dentro a fuera, la siguiente de fuera a dentro, y así sucesivamente.

${ }^{210}$ Typogr. Cesareae Imperiali-Aulica, Viena, 1716.

${ }^{211}$ S. e., Debrecen, 1725. La primera edición, de 1702, no contiene esas composiciones.

${ }^{212}$ F. Cezary, Kraków, 1718.

${ }^{213}$ Typ. Acad., Kraków, 1723.
} 
(f. F2r) una pirámide en latín que le dedicó Stanislaus Maykiewicz. Ignacy Kanty Herka compuso un poema-obelisco rematado por una estrella, impreso en Porta triumphalis, de Franciszek Józef Domaniewski. ${ }^{214}$ Un texto en prosa dispuesto en forma de flor o estrella, que es a la vez un mesóstico con un "VIVAT" en el centro, figura en Caput Palladis curae [...] in [...] D. Gasparein Cienia Cienski de Sebastian Wykowski (17001764). ${ }^{215}$ Michal Jan Nepomucen Awedyck $(+1780)$ recogió un poema-monumento en su folleto Conchylium gemmas. ${ }^{216}$ Klemens Kostka Herka (1713-1759) publica en Liber passus, ${ }^{217}$ dedicado al profesor Stanislaus Wadowski, una estrella (f. E1r) y una pirámide truncada acróstica (f. D2r) en latín. También está en latín el obelisco de Józef Wieczkiewicz que se imprimió en la última página de Naumachia triumphalis, recopilación de escritos de Ignacy Herka y Maurycy Kielwowski reunida por Stanislaw Antoni Bielecki. ${ }^{218}$ Higgins menciona (p. 140) un acroteléstico y caligrama de Johann Carl Kreutzer en forma de corona, compuesto, en alemán, en honor de la reina Catalina II de Polonia e impreso en Gdansk. ${ }^{219}$ Jakób Antoni Józef Surowiecki es autor de un colofón caligramático en prosa, en forma de diamante, que aparece en su Praedicatum panis rei. ${ }^{220}$ En Lucina orti sub sole lechico de Franciszek de S. Casimiro ${ }^{221}$ figuran una pirámide y una cruz (con un ojo en el centro) (p. 27). Festum crucis Potocianae de Franciszek Norbert Nieweglowski ${ }^{222}$ incluye un caligrama en prosa latina con el escudo de armas de la familia Potocki y otro que diseña en la última página del libro una pirámide truncada con mesóstico y teléstico. Por Dick Higgins ( $p$. 137) he sabido que la Biblioteca Jagellona de Cracovia guarda un tratado de poética manuscrito, obra del jesuíta P. Franciszek Minocki (+1784), de ca. 1756, dado a conocer por Piotr Rypson,

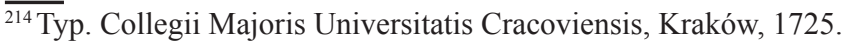

${ }^{215}$ Typ. S. R. M. Scholarum Piarum, Warszawa, 1726.

${ }^{216}$ Typis haeredum Francisci Cezary, Kraków, 1728.

${ }^{217}$ Typ. Collegii Majoris Univ. Cracoviensis, Kraków, 1732.

${ }^{218}$ Typ. Acad., Kraków, 1732.

${ }^{219}$ Está en An den Nahmens-Feste Catherina Zweyer Grossen Koeniginnen, T. J.

Schreiber, Gdansk, 1733.

${ }^{220}$ Academicis, Poznan, 1735.

${ }^{221}$ Confraternitatis Ssmae. Trinitatis, Lwow, 1736.

${ }^{222}$ Typis Universitatis, Zamosc, 1741.
} 
que, entre otros technopaegnia, contiene cinco cruces -una, la de S. Venancio Fortunato, y otras tres atribuidas a S. Francisco de Asís (f. 71r) - , una pirámide (f. 70r), una espada (f. 7), una rosa (f. 71r), una ínfula y un cetro (f. 72r), una media luna (f. $72 \mathrm{v}$ ) y un obelisco (f. 80v).

Rafael de Cózar alude en su libro $^{223}$ a un laberinto en forma de estrella (que reproduce en la p. 530) incluído por Leandro Gallardo de Bonilla en su Descripción de la proclama, Que se executò en la muy noble, y leal ciudad de Badajoz, y de las fiestas con que ésta celebró la elevación a el trono de su muy poderoso, $y$ amado Rey, y señor D. Fernando VI. ${ }^{224}$ Se trata de un "soneto esférico" (p. 6) cuya forma podría asociarse a la de una estrella tanto como a la del sol, aunque es esta última la que estaba en la intención del autor. Cada uno de sus catorce versos, que no convergen apuntando directamente hacia el centro, sino en un sentido levemente oblicuo que produce cierto efecto de movimiento giratorio, termina con las letras $S T O$, que forman el centro del dibujo. Leídas, además, en sentido circular y contrario a las agujas del reloj, las primeras letras de cada verso, ${ }^{225}$ resulta la frase "VIVAFERNANDOSE", que se completa en todos los casos con las letras centrales. Se trata, pues, de un caligrama que es laberinto y acróstico a la vez. Ya el mero hecho de estar dirigido a la persona del rey establecería una relación implícita con el sol, pues son muy habituales tanto la asociación metafórica entre éste y los monarcas absolutos como la designación del sol como "el astro rey"; pero es que, además, el texto hace referencia explícita: "Vivio el Primer Fernando, el grande auguSTO/ Iluminó, qual Sol, su Imperio vaSTO"... Otro caligrama solar, asimismo laberinto y acróstico, pero éste en forma de "décima esférica" y compuesto en honor de la reina doña Bárbara de Braganza -"VIVADBARBA", con la sílaba $R A$ en el centro-, se encuentra en la p. 7, aunque éste no lo menciona Cózar. ${ }^{226}$ La décima también nombra al sol (con

$\overline{223}$ Poesía e imagen..., p. 363.

${ }^{224}$ S. e. , Madrid, 1747, aunque Cózar -que cita el título abreviadamente- la data en 1748.

${ }^{225}$ Curiosamente, en la parte superior del sol las mayúsculas iniciales de cada verso están invertidas.

${ }^{226}$ Puede verse reproducido en el trabajo de Víctor Infantes de Miguel "Algunas de las poesías...", p. 237. 
el que se compara a la reina), lo cual deja fuera de toda duda su carácter caligramático. Rafael de Cózar sí hace referencia a otro texto en forma de estrella que aparece en una obra que él cita como anónima y denomina (p. 364) Relación de fiestas de Zaragoza en la proclamación de Carlos III, pero que en rigor se debe a Manuel Vicente Aramburu de la Cruz, catedrático de Decreto en la Universidad cesaraugustana, abogado de los Reales Consejos, etc., y se titula Zaragoza festiva en los fieles aplausos de el ingresso, y mansión en ella de el Rey nuestro señor Don Carlos III. Con la Reyna Doña María Amalia de Saxonia, y Principe de Asturias Nuestros Señores, y Señores Infantes, en su viage à la Corte de Madrid desde la de Napoles, y de su Real Proclamación por Rey de las Españas. Relación panegyrica de las alegres demonstraciones, que con tan gloriosos motivos hizo esta Augusta Imperial Ciudad. ${ }^{227}$ Se trata de un gran caligrama, que puede figurar un sol tanto como una estrella, titulado "Labyrinthus acros.", impreso en una página desplegable con dos dobleces horizontales, ${ }^{228}$ con doce versos a modo de rayos, unos en dirección centrípeta y otros centrífuga, alternativamente, con una $S$ como centro, inscrita en blanco dentro de un grabado rectangular. Las letras exteriores de cada rayo, leídas en el sentido de las agujas del reloj, forman, en un doble acróstico, el nombre de "CAROLU". En la misma obra figuran otros acrósticos no caligramáticos (p. 152 y 163). Cózar cita asimismo, y reproduce (p. 364 y 530), una curiosa composición en forma de bandera publicada por el P. Nicolás García en Desempeño el más honroso de la obligación más fina, y gratitud obsequiosa a el más sublime favor, en los festivos, ruidosos triumphos, con que fuè solemnizada la Canonización de San Camilo de Lelis, excelso patriarcha de la esclarecida religión de Padres Clérigos Reglares Ministros de los Enfermos Agonizantes. Declarada por nuestro Santísimo Padre Benedicto XIV. Celebrada en esta imperial villa, y regia corte de Madrid, y en la Ínclita moderna Athenas Complutense. ${ }^{229}$ La silueta de la pieza (p. 26) configura, en efecto, un estandarte vertical de dos puntas, pero su texto no

\footnotetext{
$\overline{{ }^{227} \text { Imprenta de el Rey Nuestro Señor, Zaragoza, } 1760 .}$

${ }^{228}$ Va numerada como la 148, pero se encuentra entre las 184 y 185 . No obstante, entre la 147 y la 149 hay otra página 148 .

${ }^{229}$ Viuda de Juan Muñoz, Madrid, [1748].
} 
hace sino repetir - a veces completas, a veces incompletas- las letras del palíndromo "ZURCA LA CRUZ", por lo que estamos ante un caligrama atípico. En esta misma obra se encuentra (p. 28) un laberinto de siete líneas con forma de rombo: la primera línea consta de una sola letra, una $L$; la segunda, de tres: "LUL"; la tercera, de cinco: "LUXUL"; la cuarta, de siete: "LUXEXUL"; y a partir de ésta se repite, pero en sentido decreciente, el mismo esquema con las mismas letras, de forma que la última línea vuelve a tener sólo una $L$. La $\boldsymbol{E}$ que ocupa el lugar central -es decir, la cuarta posición- de la línea central es de tamaño superior al de las demás letras. De ella arranca, leyendo de dentro a fuera, sea hacia arriba, hacia abajo, hacia la izquierda o hacia la derecha, la palabra "EXUL", mientras que si se comienza la lectura de fuera a dentro por la primera letra exterior de arriba, de abajo, de la derecha o de la izquierda, leemos siempre "LUXE". La semejanza entre la forma del rombo y la del sol, la importancia otorgada al "núcleo" central de la composición y las referencias a la luz autorizan a pensar que nos encontramos ante otro caligrama solar.

Ana Hatherly reproduce en su libro (fig. 46 y 47) otros dos impresos dieciochescos con technopaegnia en castellano, conservados en la Biblioteca Geral da Universidade de Coimbra, compuestos por Miguel Infante, que imprimió la compañía cómica española de Juan Antonio Estévez, que se encontraba a la sazón trabajando en Lisboa, para presentarlos como sendos homenajes. El primero, dedicado al rey don José I con motivo de su cumpleaños, contiene un "soneto acróstico céntrico" y tiene forma de rueda, según aclara una octava aneja; el otro, más complicado, dirigido al Conde de Oeyras, tiene la forma del escudo nobiliario del Marqués de Pombal.

En 1759 aparecieron, en el número 6 de la Gaceta de Lima, dos caligramas del Padre Mariano Luxán, del convento del Rosario: un mesóstico circular en castellano y un laberinto en latín con forma de diamante. ${ }^{230}$ También en Perú se editó en 1783 la Oracion funebre que en las solemnes exequias de la $R$. M. Maria Antonia de San Joseph, Larrea, Arispe, de los Reyes ${ }^{231}$

\footnotetext{
${ }^{230} \mathrm{Cf}$. Gaceta de Lima de 1762 a 1765, ed. de José Durand, Oficina de Asuntos Culturales COFIDE, Lima, 1982, p. 278.

${ }^{231}$ Imprenta de los Huérfanos, Lima, 1783.
} 
del Padre Cipriano Gerónimo de Calatayud y Borda (¿1734?1814), de la Orden de la Merced, catedrático de Artes en la Universidad de San Marcos, donde aparece (p. 200) un laberinto en forma de cruz, en latín.

Ana Hatherly copia (fig. 1) un texto en latín, atribuido a Santo Tomás de Aquino, manuscrito en forma de cruz, que se recoge en una Miscelânea anónima de los siglos XVII y XVIII conservada en la Biblioteca Geral da Universidade de Coimbra. Otra cruz, anónima, bordeada por una línea dibujada y cuyo texto consiste únicamente en mayúsculas iniciales y puntos que indican la abreviatura, está en la "Colecçao Pombalina" de la Biblioteca Nacional de Lisboa (fig. 90). Por Hatherly asimismo he podido saber que al imprimir su tesis doctoral de Derecho Civil Manuel de Gama Lobo tuvo la ocurrencia de presentar su "Conclusio VIII" disponiéndola como un laberinto en forma de estrella con una $M$ en el centro, y empleando en cada uno de los rayos, formado por tres líneas, tres tipos de letra diferentes (fig. 48). La tesis se imprimió en $1726 .{ }^{232}$ También recoge la artista e investigadora portuguesa (fig. 5) un "Laberinto intrincado, que principiando do meyo sempre se lerá EM PUBLICAR O VOSSO VALOR" dedicado a la Natividad y debido a Joze da Silva, que se imprimió en el libro de Frei Francisco da Cunha Oraçam Académica e Panegyrica, Histórica, Encomiástica, Profano-Sacra. ${ }^{233}$ El escrito, que combina de diversas maneras las letras de la frase en versales recién transcrita, adopta también la forma de una cruz. La propia Hatherly copia asimismo (fig. 4) otro laberinto-cruz -éste sobre la frase "EU SOU O MAIS EMPENHADO"- del mismo autor, la misma procedencia y el mismo asunto, y redactado en la misma lengua portuguesa. Es evidente que forma pendant con el anterior, ya que esas dos frases son continuación la una de la otra. Hatherly, por motivos que ignoro, reproduce en primer lugar el caligrama que yo he citado más tarde, estableciendo por consiguiente la secuencia «EU SOU O MAIS EMPENHADOEM PUBLICAR O VOSSO VALOR». Si yo, sin haber podido ver la Oraçam..., prefiero leer "EM PUBLICAR O VOSSO VALOR-EU SOU O MAIS EMPENHADO" es porque al pie del

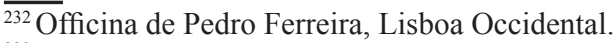

${ }^{233} \mathrm{Na}$ Officina Alvarense, Lisboa, 1743. 
laberinto-cruz organizado sobre "EM PUBLICAR O VOSSO VALOR" se indica: "De Joze da Silva a a Natividade", mientras que bajo el otro dice "Do mesmo". La misma Oraçam... contiene un "soneto acrostico esferico", igualmente en portugués, en honor de la reina de Hungría y Bohemia "a pulcra heroina senhora dona Maria Thereza VValburga de Austria", que adopta la forma de una rueda o un sol con la letra $A$ en el centro. ${ }^{234}$

\section{El siglo $X I X$}

Dick Higgins dio a conocer, en su libro ya citado de 1987 (p. 63), un poema-zampoña del Conde Mario Bevilacqua, añadido a la colección de empresas de Camillo Camilli ${ }^{235}$ (I, p.132). En el Saggio del prospetto generale di tutti $i$ verbi anomali e difettivi si semplici che composti e di tutte le loro varie configurazioni di voci dall'origine della lingua in poi, de V. Nanucci, ${ }^{236}$ aparece, según indica Pozzi (p. 280), un texto dispuesto en forma de copa (o acaso clepsidra, agrega el estudioso), con el título "Al dio magnano, mio bel messere". Aunque en él no se haga referencia alguna, como el propio Pozzi observa, a la bebida, parece claro que el lector ha de entender que el dios aludido por el título es el vino (o el dios del vino, Dionisos o Baco) y, por consiguiente, relacionar el texto del $\tau \varepsilon \chi v o \pi \alpha i ́ \gamma v i o v$ con el objeto representado en éste.

En las Obras Completas del poeta uruguayo Francisco Acuña de Figueroa (1791 1862), ${ }^{237}$ figura un buen número de caligramas, algunos en portugués La mayoría de ellos se disponen en forma de copa (vol. V, p. 178, 200, 248; vol. VI, p. 15, 197, 264; vol. VIII, p. 173, 192; vol. VIII, p. 27, 330, 351), pero hay también poemas-cruz (vol. V, p. 50, 203-206; vol. VI. p. 339), poemas-reloj de arena (vol. V, p. 63) y poemas-botella (vol. VII, p. 194). Muchas de estas composiciones fueron escritas para los álbumes de damas burguesas, según la moda romántica. Algunos títulos ya son significativos: "La copa y el néctar. En el álbum de Pilar"., "Al álbum de doña Luisita Blanco", "Una copa. Al

\footnotetext{
$\overline{{ }^{234} \mathrm{Cf}}$. A experiência..., fig. 45 .

${ }^{235}$ Imprese illustri, F. Ziletti, Venezia, 1586.

${ }^{236}$ Tipografia di Tommaso Baracchi, successore di G. Piatti, Firenze, 1853.

${ }^{237}$ Vázquez Cores, Dornaleche y Reyes, Editores, Montevideo, 1890, 12 vols.
} 
álbum de Rosalía", etc. Varios de estos caligramas son a la vez acrósticos. ${ }^{238}$

En España, las primeras referencias a caligramas que pude documentar en el siglo XIX (p. 46 y 47 de mi libro) estaban en el curiosísimo Esfuerzos del ingenio literario de L. M. Carbonero y Sol (1890), y se referían a dos ejemplares franceses y uno mejicano. Es notorio que el autor ignoraba -como yo mismo en 1977- la obra de don José González Estrada (ca. 1830-1883), estrambótico editor del estrambótico periódico El Pistón, que apareció en 1864 y 1865 -una verdadera mina para el interesado por toda clase de aberraciones literarias- ${ }^{239}$ y autor de El Siglo Poético. Dividido en cuatro tomos de igual tamaño ${ }^{240}$ y de un volumen facticio de Poesías impreso en el establecimiento de F. Hernández, s. d. [ca. 1862]. Orate incuestionable, él mismo refiere en su revista que toda su casa estaba decorada con laberintos y pentacrósticos enmarcados, y también que cuarenta y ocho estudiantes habían solicitado al Gobierno la creación de una cátedra de poesía laberíntica y su adjudicación a González Estrada $^{241}$, cosa de la que él se enorgullece pero que difícilmente pudo no ser una broma. Tengo la impresión de que Dick Higgins, a cuyas cartas debo el descubrimiento de este personaje y su obra, y que en su libro de 1987 (p. 113-122) prestó a uno y otra una atención desmesurada, no llegó a percatarse, quizá por su deficiente conocimiento de la lengua española, de la auténtica idiosincrasia de González Estrada y de la monstruosidad literaria de lo que escribió.

El Pistón, que contiene, aparte de trabajos de su director, colaboraciones de otros muchos -incluido, supongo que sin conocimiento suyo, Victor Hugo- es todo un muestrario de chifladuras, entreveradas con ataques a Hartzenbusch. Su número 12 , por ejemplo, de junio de 1864, lleva, a uno y otro lado del título, sendas estrofas, que dicen (conservo las peculiaridades ortográficas):

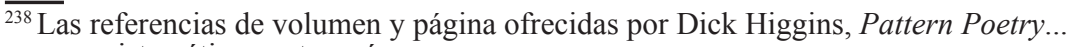
son sistemáticamente erróneas.

${ }^{239}$ Sobre esta publicación, $c f$. el trabajo de Javier Ruiz citado en la nota 4 y el generoso espacio que le dedica Dick Higgins, Pattern Poetry..., p. 113-122.

${ }^{240}$ Burdeos, Imprenta Jacquet, 1861.

${ }^{241}$ Cf. Javier Ruiz, "Laberintos y Pentacrósticos...”, p. 116.
} 
Lira y aprieto, La poesia

de sonsonete, del piston;

con clarinete, y acordeon

en desconcierto. con armonía.

Poco más abajo aparece una poesía, "Flor amorosa", cuyas dos primeras estrofas (y no harán falta más para formarse un juicio crítico) dicen así:

Don José Salamanca

Es persona de gusto

Con su ninfa muy justo

Siendo de garbo y guapa.

Resuenen siempre los ricos

Dadibosos y con lujo

Que logran con su influjo

Gracias para los líricos.

En la primera página del número 19, agosto del mismo año, hay una especie de editorial que invita a los colaboradores de la revista a seguir componiendo "poesías laberínticas, para engrandecimiento de la literatura española" y que culmina proclamando que (sigo manteniendo la ortografía del original).

Los escritores de este siglo y catedráticos de poetica, solo son rutinarios simples copleros y por cuya razon se quejan los escolares del engaño que han sufrido, pues á los alumnos de poética, solo los han enseñado poesía sencilla, comun coplera y romancera que es una vulgaridad.

Ya en el número 4 había arremetido, en un párrafo que reproduce Javier Ruiz, ${ }^{242}$ contra los catedráticos y académicos, que

son unos farsantes, que el que más sabe es espresar esa poesía sencilla, libre, común, coplera, por el orden que los ciegos sacan sus coplas, para las personas rústicas que es una vulgaridad.

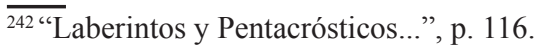


Javier Ruiz y Dick Higgins han reproducido algunos caligramas de diversa autoría publicados en El Pistón: un "jarro literario" dedicado a Estrada por un colaborador anónimo consiste en dos flores grabadas, un poema al pie, con algunas de sus palabras escritas en versales que diseñan, según la técnica de los "versi intexti", el perfil de un jarrón, y, entre el jarrón y las flores, dos líneas de texto que imitan los tallos de éstas y, en medio, una cruz también caligramática. Un tal Pitágoras firma un "Corazón acróstico laberíntico", de forma bastante tosca. De José González Álvarez es "Un capricho", con la silueta de, más o menos, un reloj de arena.

En El Siglo Poético, junto a penosos acrósticos, sonetos pentacrósticos y algún que otro "pentacróstico cruzado" o "forzado" que evidencian una admirable incompetencia para el metro, encontramos tres poemas-cruz dedicados a Martínez de la Rosa, Álvarez Mendizábal y Pedro Calvo Asensio respectivamente (el segundo, de efecto involuntariamente irónico, habida cuenta de quién era su destinatario) y un poema-arpa que es al mismo tiempo soneto, acróstico y autoelogio del pobre don José. Del contenido de las Poesías me reconozco incapaz de hacer un resumen descriptivo: hay que verlas.

Gentes de, más o menos, la condición de González Estrada motivaron que José María de Pereda (1833-1906) aludiese burlonamente en el capítulo XV de su muy instructiva novela Pedro Sánchez $z^{243}$ a las "estrofas en forma de cáliz, de guitarra, de cruz, de pirámide y de reloj de arena" que, con otras extravagancias, llenaban los álbumes de las señoritas de la burguesía madrileña de mediados del siglo XIX.

Rafael de Cózar recuerda (p. 151, 173 y 355) que el propio Carbonero y Sol dirigió la revista La Cruz (Madrid, 1852-1886), donde se publicaron caligramas, muchos de ellos precisamente cruciformes, entre los que se encuentra el que se dice atribuido a Santo Tomás de Aquino. Higgins (p. 38) hace referencia a uno aparecido en el número de abril de 1872, otro en el número 2 de 1864 (p. 638), otro del número 1 de 1876 (p. 380) y otro de agosto de 1886, todos menos éste último recogidos en el libro de Carbonero y Sol.

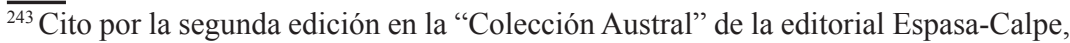
S. A., Madrid, 1965, p. 86. 
Por su parte, Eduardo de Ory presenta en su ya citado Rarezas Literarias tres poemas-cruz -uno de C. Rodríguez (p. 117) y dos anónimos (p. 118 y 119) - ${ }^{244}$ y cuatro en forma de copa: uno anónimo (p. 120) y tres que constituyen la composición "El tres de copas. Tríptico 'bebestible"” de Carlos Miranda (p. 121-123), la cual, según Ory dice, se publicó el 28 de octubre de 1911 en el número 26 de La Hoja de Parra.

Ana Hatherly dio a conocer en su libro (p. 153) un Soneto acrostico ao Soberano CONGRESSO representativo da Naçâo Portugueza, No dia 26 de Janeiro de 1823, anniversario da sua installaçâo, impreso en una hoja suelta sin datos editoriales. El texto, que, según un gusto típicamente barroco, es, además de acróstico, también mesóstico y teléstico, tiene forma de rueda con una $A$ en el centro. Una nota al pie nos explica que tomando sucesivamente las primeras letras de los 14 versos resulta el sintagma "Sabio Congresso"; con otras letras situadas en la sexta sílaba de cada verso se forma la expresión "Dos lusos gloria"; todos los versos terminan en la $A$ central, y, además, en la composición se usaron todas las letras del alfabeto portugués. Pero en ella no hay ninguna referencia o alusión a ninguna rueda, de modo que no podemos calificarla propiamente de caligrama aunque sí sea carmen figuratum.

Dick Higgins aclara en su importante estudio (p. 88) que en el periódico dirigido en Viena por Alfred Bäuerle que se tituló Wiener Allgemeinen Theaterzeitung, Wiener Illustrierte Theaterzeitung y de otros modos, aparecieron, además del caligrama en forma de muñeco de Ferdinand August Oldenburg, ${ }^{245}$ que -aunque atribuyéndoselo, como otros, al propio Bäuerle- mencioné y reproduje en mi libro (p. 110), una copa del propio Bäuerle, ${ }^{246}$ y un jarrón de C. J. Metzger. ${ }^{247}$ El mismo Higgins alude en la misma página a un poema anónimo, en alemán, publicado en la revista Kladderdatsch el 25 de diciembre de 1853, en el que los versos configuran, en consonancia con la fecha y la intención, el perfil de un árbol de

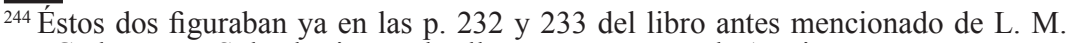

Carbonero y Sol. El primero de ellos, según éste, es de A. Rivero.

${ }^{245}$ Núm. 20, 1845, p. 4.

${ }^{246}$ Núm. 137, 1818, p. 1.

${ }^{247}$ Núm. 89, 1823, p. 1.
} 
Navidad. El bávaro Joseph Gutsmüthl, conocido también como "Shalomohn Schönenfels", publicó en su extravagante ShorhrohS de 1853 un poema con forma de jarrón (p. 73).

Gracias a Dick Higgins (p. 69-70) he tenido también noticia de la existencia de un caligrama en francés con forma de reloj de sol, titulado "Crépuscule", impreso por el poeta canadiense francófono Albert Ferland (1872-1943) en la p. 280 de su libro Les soirées du Château de Ramezay (1900). Es el único ejemplar canadiense que se conoce hasta el siglo XX.

Higgins, que apunta (p. 105) que no se ha encontrado ningún caligrama inglés del siglo XVIII, sí menciona unos cuantos del XIX: cuatro cruces anónimas y un arco -imitación de un modelo oriental- que cita Charles Carroll Bombaugh en Oddities and curiosities of words and literature ${ }^{248}$ un violín, igualmente anónimo, que recoge William Shepard Walsh en Handy-book of literary curiosities (1895), ${ }^{249} \mathrm{y}$ una botella, una mujer y un curioso poema sobre la pérdida de peso, anónimos asimismo, editados por Carolyn Wells en $A$ whimsey anthology (1906). ${ }^{250}$

La biblioteca del Trinity College de Dublín guarda un manuscrito, The Book of Armagh, en que se encuentra un caligrama del XIX en prosa gaélica, en forma de diamante (f. 160v). En gaélico galés está escrito un caligrama sobre la Torre de Babel, debido a Hywel Tudur ( $f$. a fines del XIX), que se publicó en su libro Genesis i blant. ${ }^{251}$ Robert Williams, conocido como "Trebor Mai" (18301877), compuso en la misma lengua un poema-roble cuyo texto nombra a los más importantes poetas galeses. Puede verse en sus Collected Works ${ }^{252}$ (p. 383).

El norteamericano H. C. Dodge es autor de un caligrama en forma de jarrón que editó Carolyn Wells. ${ }^{253}$ Uno con forma de diamante y texto en estilo de telegrama se imprimió, atribuyéndoselo al General Grant, en el volumen 1, número 3, de la revista The Rose Lawn Home Journal en 1871 (p. 4). Mary Hazard, miembro de la secta shaker, hizo un poema de forma circular en 1848, y

\footnotetext{
$\overline{248}$ Martin Gardner, 1875. Reimpreso en Dover Publications, New York, 1961.

249 Reimpreso por J. B. Lipincott, Philadelphia, s. a. [ca.1925].

250 Reimpreso por Dover Publications, New York, 1963.

251 S. e., Caernarfon, 1906.

252 I. Foulkes, Liverpool, 1883.

${ }^{253}$ A whimsey..., p. 21.
} 
también una corona de flores y una hoja, según informa Higgins (p. 109).

Éste menciona asimismo algunos ejemplos polacos del XIX, todos anónimos, aunque no deja de señalar que a lo largo de ese siglo en Polonia, "as elsewhere, Pattern Poetry is very rare" ( $\mathrm{p}$. 138): una botella de 1822 , una copa de 1840 y un original caligrama en prosa titulado "Biedny poeta" ("Poeta pobre") aparecido en el periódico Kurier Swiateczny en 1896. En él se representan la ilusión con que el autor sube con su original al despacho de un editor y la decepción con la que sale de él, rechazado, mediante, primero, una disposición del texto en forma de escalones y, después, una línea oblicua descendente.

El propio Higgins habla (p. 58) de un poema-cruz en húngaro publicado por Gyula Bulyovszky en el periódico Hazánk el 27 de marzo de 1847. También (p. 94) de otra cruz anónima en holandés, impresa por C. L. van Langenhuysen en 1855, y de un poema-corazón anónimo y de fecha ignorada, asimismo en holandés.

\section{Los primeros años del siglo $\mathrm{XX}$}

Un artículo de Eugenio d'Ors publicado en Nuevo Mundo en $1923^{254}$ me dio la pista de un libro de un escritor uruguayo que precedió a Apollinaire en la creación de caligramas: se trata de Palideces $i$ [sic] púrpuras -título evidentemente más modernista que vanguardista ${ }^{255}$ de Carlos López Rocha, editado en $1905^{256}$. En él se contienen, para ser exactos, dos ejemplos: uno, sin título, es un texto en prosa, entre simbólico y esotérico, impreso en forma de cáliz, que alude en sus últimas líneas al Santo Grial (p. 77). Se presenta como nota al soneto alejandrino "Azvcena", que ocupa la página anterior. El otro, éste en verso y titulado "Brindis", es otra copa (p. 114), pero rodeada por un dibujo. Dado que los $\tau \varepsilon \chi v o \pi \alpha i ́ \gamma v i \alpha$ en forma de copa son muy característicos en la tradición anterior del género, no creo que deba considerarse a López

\footnotetext{
254 "Palique", Nuevo Mundo, 4 may. 1923, ahora recogido en Paliques (1922-1925), Áltera, Barcelona, 2006, I, p. 91.

${ }^{255}$ Modernistas son igualmente las composiciones que recoge el volumen, prologado por Julio Herrera y Reissig, y el diseño tipográfico, con dibujos de Emilio López Rocha.

${ }^{256}$ Imprenta Galileo, Buenos Aires.
} 
Rocha precursor de Apollinaire sino más bien continuador de aquella tradición..

Ese mismo año 1905 aparece un sutil -y mucho más originalcaligrama en catalán en Les tenebroses, ${ }^{257}$ de Rafael Nogueras Oller (1880-1949). Su título es "Una esse" (p. 59) y su texto, alusivo a un borracho, se dispone en forma de $S$ : un buen argumento para defender, como defiendo, que la disposición gráfica del caligrama no ha de representar necesariamente su contenido, sino éste o cualquier objeto relacionado de alguna forma con él.

El chileno Vicente Huidobro (1893-1948) -que ya en 1912 había publicado, en una revista de Santiago de Chile, un "Triángulo armónico"258 que no es un caligrama pero sí un poema visual en forma de rombo, asociable a las "escalas métricas"- recoge en su libro Canciones en la noche (Santiago, 1913), además de esa misma composición y otra "escala métrica" titulada "Fresco nipón", dos verdaderos caligramas: ${ }^{259}$ "Nipona" tiene la forma simétrica de una pagoda reflejada en un estanque (al que hace alusión el texto); "La capilla aldeana" representa lo que este título indica, haciendo una ligera variante del tradicional y manido caligrama en forma de cruz. ${ }^{260}$ La obra caligramática del poeta chileno aparece, pues, ante el observador como un eslabón entre la tradición clásica y la vanguardia, que a estas alturas ya es otra tradición.

$\overline{257}$ Joventut, Barcelona, 1905.

${ }^{258}$ Musa Joven, 1, 6, oct. 1912, p. 43.

${ }^{259}$ Juan Manuel Bonet ha recordado, "El caligrama y sus...”, p. 20, que Huidobro "pensaba realizar un álbum de poemas dibujados", que nunca llegaría a publicarse.

${ }^{260}$ Pueden verse ahora en Vicente Huidobro, Obra poética, ed. crítica coordinada por Cedomil Goic, ALLCA XX, Madrid-Buenos Aires-La Habana [...], 2003, p. 213 y 214. 